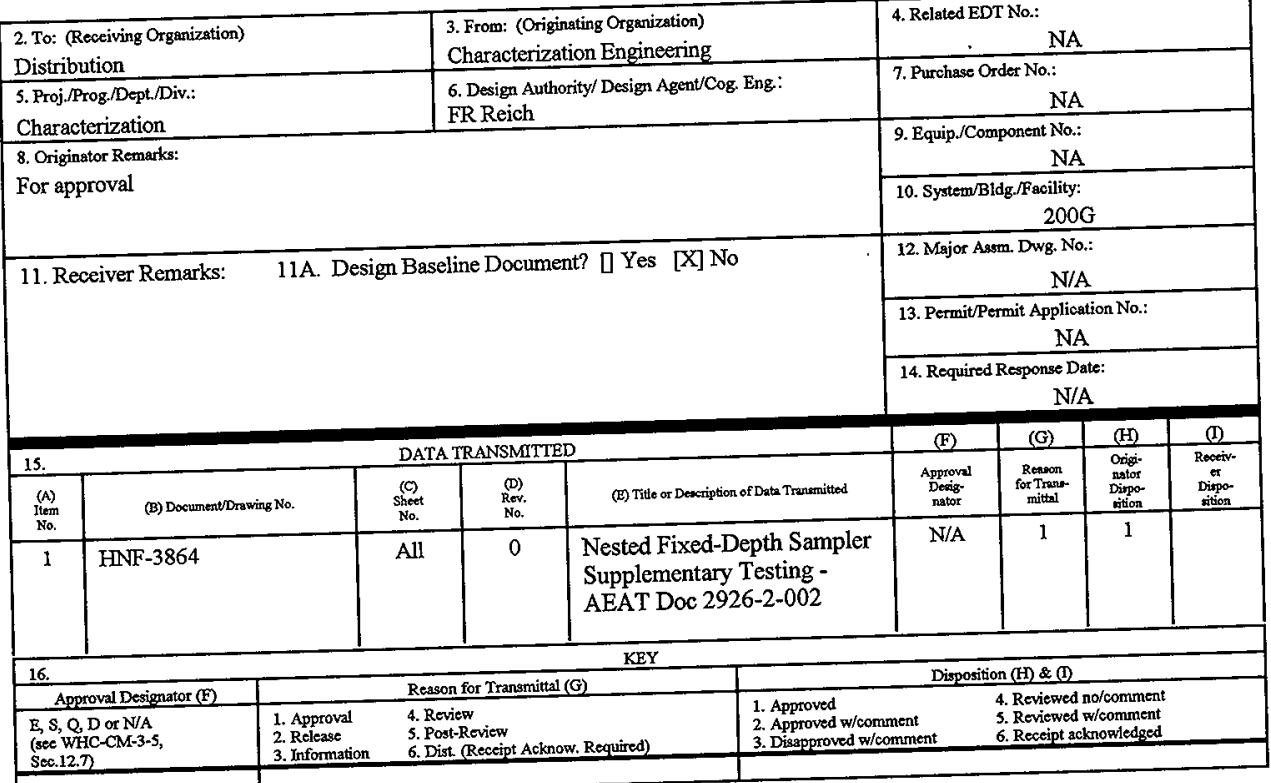

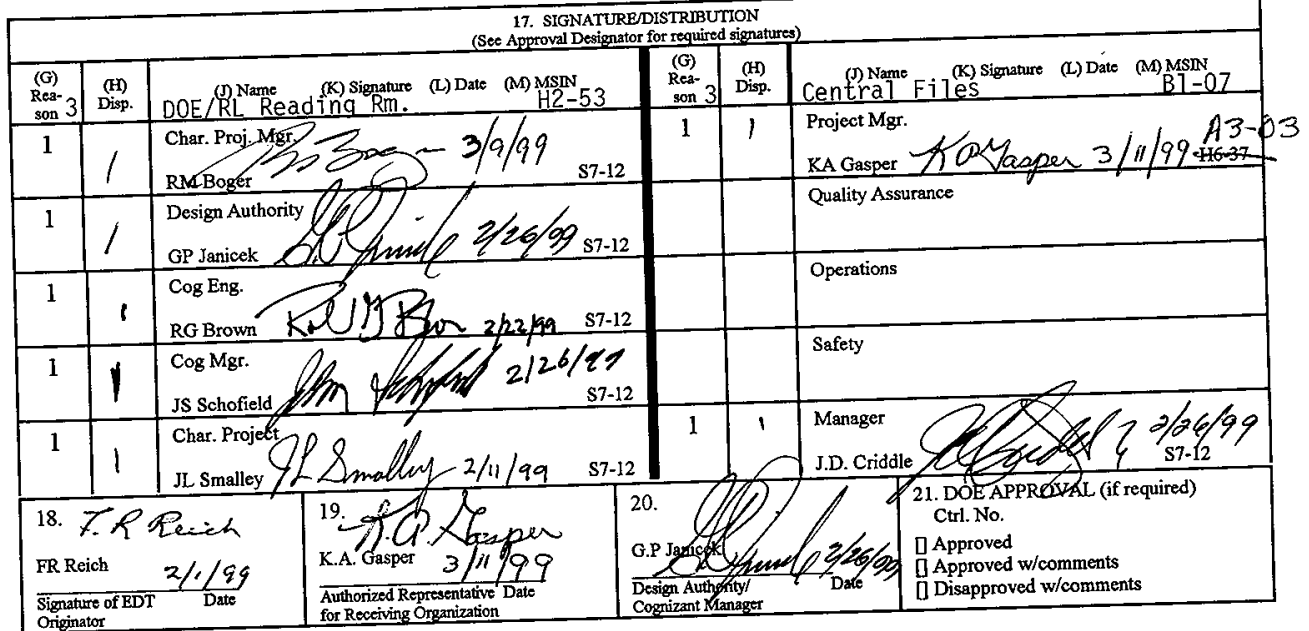




\title{
Nested, Fixed-Depth Fluidic Sampler Supplementary Testing - AEAT Doc 2926-2-002
}

\author{
F. R. Reich \\ Prepared for Lockheed Martin Hanford, Inc. \\ Richland, WA 99352 \\ U.S. Department of Energy Contract DE-AC06-96RL13200
}

EDT/ECN: 623352

UC: 2070

Org Code: $\$ 1700$

Charge Code: 108418/BA10

B\&R Code: EW3120074

Total Pages: $48 \mathrm{gan} 46$

HN921111

Key Words: Waste Sampling System, Light Activity Wastes, Double-Shell Tank Sampler, Sampling System Performance Tests, Nested, Fixed-Depth Sampling System

\begin{abstract}
This report summarizes the results of cold testing, completed by AEAT, as part of the proofof-principle testing for a proposed nested, fixed-depth fluidic sampling system. This sampling system will provide waste samples from the PHMC feed tank to support the privatization contract with BNFL. Proofof-principle tests were completed with $2 \mathrm{wt} \%$ and $10 \mathrm{wt} \%$ sand/water and $25 \mathrm{wt} \%$ kaolin clay/water simulants with a test setup that spanned the $24 \mathrm{ft}$ to $57 \mathrm{ft}$ height required in the feed tank. The tests demonstrated that the system could "pump" and sample waste materials with low and with high solids content. In addition, the tests demonstrated a need for some design upgrades to the sampling system, as there was material loss when the sample bottle was removed from the sampling needle. These were complementary tests, completed as part of an EM-50 Tank Focus Area (TFA) to develop a sampling system for validating LAW and HLW waste batches for the Privatization Contract (Contract DE-AC0696RL13308, Mod. No. A006, 1996, U.S. Department of Energy, Richland, Washington).
\end{abstract}

TRADEMARK DISCLAIMER Reference herein to any specific commercial product, process, or service by trade name, trademark, manufacturer, or otherwise, does not necessarily constitute or imply its endorsement, recommendation, or favoring by the United States Government or any agency thereof or its contractors or subcontractors.

Printed in the United States of America. To obtain copies of this document, contact: Document Control Services, P.O. Box 950, Mailstop H6-08, Richland WA 993\$2, Phone (509) 372-2420; Fax (509) 376-4989.

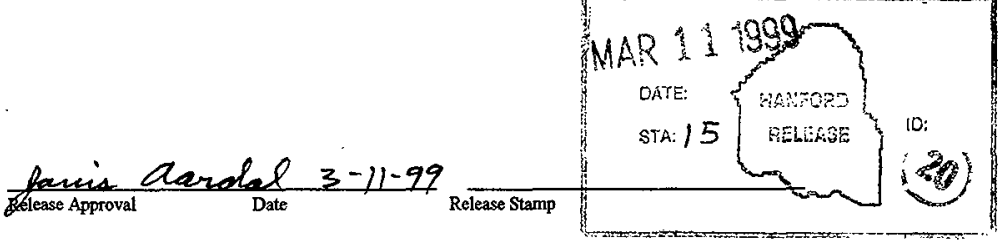


HNF-3864, REV. 0

Nested Fixed-Depth Fluidic Sampler

Supplementary Testing -

AEAT Doc 2926-2-002

Prepared for Lockheed Martin Hanford Corporation

Richland, Washington

F. R. REICH

COGEMA Engineering Corporation

Richland, Washington

January 1999 
HNF-3864, REV. 0

\section{TABLE OF CONTENTS}

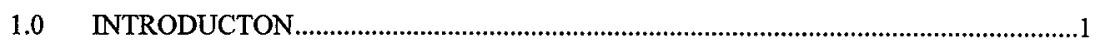

$2.0 \quad$ SCOPE

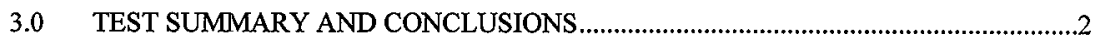

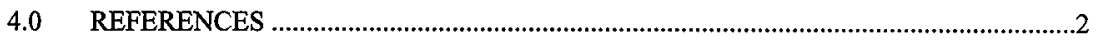

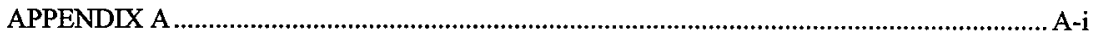

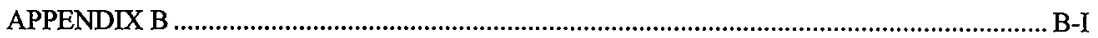


NESTED FDXED-DEPTH FLUIDIC SAMPLER

SUPPLEMENTARY TESTING -AEAT DOC 2926-2-002

\section{$1.0 \quad$ INTRODUCTION}

The attached report (Appendix B) describes cold tests carried out by AEA Technology Engineering Services Corporation (AEAT) as part of the proof-of-principle testing for the proposed nested, fixed-depth fluidic sampling system. As indicated in Appendix A, this work was completed as part of an EM-50 Tank Focus Area (TFA) activity to develop a sampling system that will provide LAW (and HLW) waste samples to support the Privatization Contract (Tank Waste Remediation System Privatization Contract DE-AC06-96RL13308, Mod. No. A006, 1996, U.S. Department of Energy, Richland Operations Office, Richland, Washington). The nested, fixed-depth sampling system will be used to extract waste samples for waste batches of waste envelopes A, B, C, and D that the PHMC will supply to the privatization contractor. The waste samples will be used for laboratory testing to certify the content of a waste batch prior to transfer to the privatization contractor. The sampling system must provide samples that are representative of the waste batch in the feed tank.

\section{$2.0 \quad$ SCOPE}

The report in Appendix B summarizes the results of testing that is complementary to the testing work competed completed by AEAT in fiscal year (FY) 1998 under an EM-50 International Programs Grant (Design, Fabrication \& Demonstration of a Nested Fixed Depth Fluidic Sampler, December 1998, prepared for the US Department of Energy by AEAT). These complementary tests uses an expanded test system to cover the 24-ft to $57-\mathrm{ft}$ sample lift height range that is expected in the PHMC feed tank. The objective of the testing was to demonstrate that the sampling system can provide samples that are physically (particle content and total solids content) representative of the wastes in the feed tank. The test activities in this complementary testing included the following:

- Determining the system drive parameters for optimum delivery of sample with a water simulant for sample lift heights of $24 \mathrm{ft}, 42 \mathrm{ft}$, and $57 \mathrm{ft}$. The driver pressure to produce "spitting" from the bottle filling hardware when no bottle was present was also measured was also measured at each lift height.

- Measuring the sample delivery rate (liters/minute sample delivered to the sample bottle) as a function of lift height and other system parameters.

- Demonstrating the sampling performance with the $25 \mathrm{wt} \%$ kaolin clay/water simulant.

The simulants used in this testing consisted of $2 \mathrm{wt} \%$ and $10 \mathrm{wt} \%$ sand/water slurries and a 25 $\mathrm{wt} \%$ kaolin(clay)/water slurry. 


\subsection{TEST SUMMARY AND CONCLUSIONS}

Solids content and particulate distributions were the two parameters selected for assessing the performance of the sampling system in the tests. However, in reviewing the data in this report, the following must be considered:

The test procedures that were followed did not include the use of blank samples that would have characterized the measurement methods independent of the sampling system. As a result, the total solids content data also contains the errors from the measurement method. Including blank samples would have allowed these errors to be separated from the errors of the sampling system and from the "grab" samples.

The solids content within the samples was too large for the optical-based analysis method that was selected for analyzing particle content. As a result, this report also does not contain any particulate distribution data. No alternate measurement method were identified or used.

The number of samples taken in each test, with the large standard deviations within these sample populations, was too small to confidently assess the performance of the sampling system.

Because of these deficiencies, a repeat of the performance tests will be required. The test objective is to assess the sampling system's ability to provide representative (physical properties) samples. This testing shall include:

- The influence of the lift height on the design of the bottle-filling hardware and control system settings for sampling channels covering the $24-\mathrm{ft}$ to $57-\mathrm{ft}$ lift heights

- The ability to deliver a representative sample over the $24-\mathrm{ft}$ to $57-\mathrm{ft}$ lift height range using a measurement methods (particle and solids content measurements) that are more suitable to the simulant's properties and includes blank measurements to characterize the performance of the measurement method. The blank data will allow the measurement method's error to be separated from the sampling system's errors.

The Students-t criteria shall be used to identify the number of samples to support a statistical assessment of the solids content and particle content data (Freund, 1952).

\subsection{REFERENCES}

Design, Fabrication \& Demonstration of a Nested Fixed Depth Sampler, December 1998, Prepared for the US Department of Energy by AEA Technology Engineering Services, Inc., 13245 Reese Boulevard West, Suite 100, Campbell Building, Huntersville, NC 28078.

J.E. Freund, 1952, Modern Elementary Statistics, Prentice-Hall, Englewood Cliffs, NJ. 


\section{APPENDIX A}

LETTER TO DR. K. A. GASPER, LOCKHEED MARTIN HANFORD CORPORATION, FROM F. R. REICH, COGEMA ENGINEERING CORPORATION, "SUMMARY REPORT FROM AEA TECHNOLOGY ENGINEERING SERVICES CORPORATION" 
Dear Dr. Gasper:

\section{SUMMARY REPORT FROM AEA TECHNOLOGY ENGINEERING SERVICES, INC.}

The enclosed report from AEA Technology Engineering Services, Inc. (AEAT) summarizes their supplementary test work that was completed on the conceptual nested, fixed-depth sampling system. This testing is part of the work scope that was completed for the Lockheed Martin Hanford Corporation (LHMC) by COGEMA Engineering Corporation (COGEMA Engineering) for Task Order LME-330.

The test work summarized in this report is complementary to the proof-of -principle testing and conceptual design work that was previously completed by AEAT for EM-50 through an International Programs grant. The scope of the testing included:

- Expanding the existing fluidic sampling test rig for sampling at 24,42 , and $57 \mathrm{ft}$ "lift" heights.

- Measuring vacuum levels in sampling bottles over this range of sample "lifts".

- Measuring the rate of sampling for each "lift" height.

- Assessing sampling performance through the measurement and comparison of solid weight content and particle size distributions with reference "grab" samples.

- Test sampling performance with a 25-30 wt\% sludge stimulant at each sample "lift" height. 
The submittal of this report completes the COGEMA Engineering scope of work for Task Order LME-330, "PHMC-AP-102-Feed Tank Project".

If you have any technical questions, please contact me at (509) 376-4063.

Sincerely,

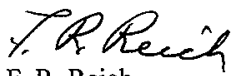

F. R. Reich

Electrical I\&C

$\mathrm{dt}$

Enclosure 


\section{APPENDIX B}

NESTED, FIXED-DEPTH FLUIDIC SAMPLER SUPPLEMENTARY TESTING 


\title{
NESTED FIXED DEPTH FLUIDIC SAMPLER SUPPLEMENTARY TESTING
}

\section{Prepared for}

\section{Cogema Hanford Inc.}

December 1998

Prepared by

Date

Approved by

Date
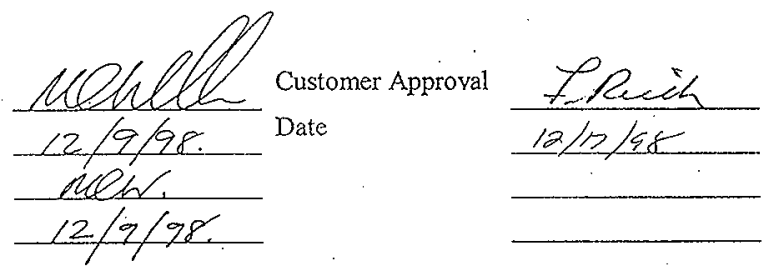

\author{
AEA TECHNOLOGY \\ ENGINEERING SERVICES, INC \\ 13245 Reese Boulevard West \\ Suite 100, Campbell Building \\ Huntersville, NC 28078 \\ (704) $875-9573$
}

\section{6-4-002}

Document No.

\begin{tabular}{|r|l|l|l|l|l|l|}
\hline $\begin{array}{r}\text { REV } \\
\text { DATE }\end{array}$ & & & & &. & $\cdots$ \\
\hline APPN & & & & & & \\
\hline
\end{tabular}




\section{Executive Summary}

This report describes a series of tests carried out as part of the proof of principle testing for the proposed 'Nested, Fixed-Depth Fluidic Sampler' (NFDS). The tests were carried out at the AEA Technology facility in Charlotte, NC in September 1998. The testing described in this report was supplementary to the proof of principle testing and conceptual design being carried out under the 1998 PTP.

The objective of the program of work described in this report is to carry out performance testing and measure system parameters for an extended sampling channel representative of sampling the full waste depth in the PHMC AP-102 feed tank.

Tests were carried out using a modified test rig and a range of specified simulants to investigate the performance of the sampler over a range of sample point to sampler separations, representative of the proposed configuration of the sampler and the anticipated waste materials in the PHMC AP-102 feed tank. The influence of sampling height on controller settings was investigated, before samples of each of the simulants were taken concurrently with a series of comparative 'grab samples' taken by traditional sampling methods. A range of readings of vacuum levels induced in the sample bottles by the sampling operation was also taken. Samples of simulants were sent to an accredited testing laboratory for analysis.

The sampler was proven to be capable of satisfactorily delivering samples of the specified simulants over. the full range of sample point to sampler separations. When analyzed, physical properties of samples of kaolin simulant were found to compare favorably with corresponding grab samples. However variation in the physical properties of the silica simulant samples were apparent when compared with corresponding 'grab' samples. It is concluded that this is mainly attributable to the variability of the grab sampling technique, and to the limitations of the analysis methods available in reliably analyzing simulants of this nature.

The report concludes by recommending further investigation of the sampler performance to investigate the unresolved issues arising from this test program more thoroughly. 


\section{Contents}

Executive Summary

B1

1 Introduction

1.1. GENERAL

1.2 BACKGROUND

B4

1.3 SCOPE OF TESTING

B4

2 Description of the Test Facilities

2.1 SAMPLER SYSTEM OPERATION

2.1.1 General

B6

2.1.1 Cycle Operation

2.1 .2

Pumping Elements

B7

2.1.3

Primary Controller

B8

2.1.4. Secondary Controller

$2.2 \quad$ TEST RIG DESCRIPTION

$\begin{array}{lll}2.3 & \text { SAMPLING PROCEDURE } & \text { B14 }\end{array}$

$\begin{array}{lll}2.4 & \text { TEST SIMULANTS } & \text { B16 }\end{array}$

2.5 TEST MEASUREMENTS $\quad$ B16

$\begin{array}{ll}\text { 2.5.1 Measurement Methods } & \text { B16 }\end{array}$

$\begin{array}{ll}\text { 2.5.2 Measurement Accuracy } & \text { B16 }\end{array}$

3 Test Methodology $\quad$ B18

$\begin{array}{lll}3.1 & \text { GENERAL } & \text { B18 }\end{array}$

$\begin{array}{lll}3.2 & \text { CONTROLLER CALIBRATION } & \text { B18 }\end{array}$

$\begin{array}{lll}3.3 & 2 \text { WT } \% \text { SAND SIMULANT TESTS } & \text { B19 }\end{array}$

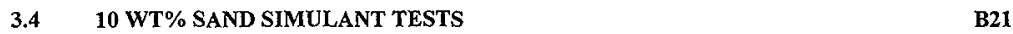

3.5 KAOLIN SIMULANT TESTS B22

4 Test Results $\quad$ B23

4.1 CONTROLLER CALIBRATION · · B23

$\begin{array}{lll}4.2 & \text { SILICA SIMULANT TESTS } & \text { B23 }\end{array}$

$\begin{array}{lll}4.3 & \text { KAOLIN SIMULANT TESTS } & \text { B24 }\end{array}$

$\begin{array}{lll}4.4 & \text { VACUUM TESTS } & \text { B25 }\end{array}$

5 Conclusions $\quad$ B27

$\begin{array}{ll}\text { 5.1 CONTROLLER CALIBRATION } & \text { B27 }\end{array}$ 
$\begin{array}{ll}\text { 5.3 KAOLIN SIMULANT TESTS } & \text { B27 }\end{array}$

5.4 VACUUM TESTS $\quad$ B28

7 References $\quad$ B30

8 Tables $\quad$ B31

\begin{tabular}{lll}
\hline Photographs & B33 \\
\hline
\end{tabular} 


\section{Introduction}

\subsection{GENERAL}

This report describes a series of tests carried out as part of the proof of principle testing for the proposed 'Nested, Fixed-Depth Fluidic Sampler' (NFDS). The tests were carried out at the AEA Technology facility in Charlotte, NC in September 1998. The testing described in this report was supplementary to the proof of principle testing and conceptual design being carried out under the 1998 PTP. The results of the PTP work are set out in a separate document. This report should be read in conjunction with the PTP report (Ref 1 ).

\subsection{BACKGROUND}

The nested, fixed-depth fluidic sampler was the subject of a Project Technical Plan (PTP) for a "Nested Array Variable Depth Sampler' executed by AEA Technology during the 1998 FY. The broad scope of the PTP was to prepare a conceptual design of a nested array sampler and sample station together with fabrication and operation of a test rig to provide proof of principle testing of the sampler principles.

The scope of proof of principle testing carried out under the PTP was based on a test plan prepared by Cogema, Hanford Inc and issued as a draft to AEA Technology in July 1998 (Ref 2). The test plan was prepared to provide guidance for the proof of principle testing of the sampler system. The test plan document set out a comprehensive and extensive program of testing designed to examine key aspects of the performance of the sampler system. Due to resource and timescale restrictions it was reported by AEA Technology at the Status Review meeting of July $8^{\text {th }} 1998$ that only certain elements of the testing program could be completed within the scope of the 1998 PTP, namely

- Cross Contamination Test

Sample Channel Cross Contamination

- Waste Physical Properties

- Startup and Operation from a Plugged Condition

This PTP testing was carried out on a test rig incorporating a prototype sampling channel. The test rig has a maximum "lift" height of approximately $24 \mathrm{ft}$ ("lift" height is the distance between the sample channel inlet(RFD) and the sample bottle). The AP-102 feed tank at Hanford, into which the nested, fixed-depth sampler will ultimately be deployed, is capable of being filled with 35 feet of waste. With the soil overburden on top of the tank, this will require lifting waste from the bottom of the tank (623.9-ft elevation) to above the tank riser (679-ft elevation for riser flange and grade level). To deliver waste to the sampling point approximately $2 \mathrm{ft}$ above the riser, the nested, fixed-depth sampling system will have to "lift" waste over a 22 to $55 \mathrm{ft}$ height range.

The objective of the program of work described in this report is to carry out performance testing and measure system parameters for an extended sampling channel representative of sampling the full waste depth in the PHMC AP-102 feed tank.

\subsection{SCOPE OF TESTING}

The scope of testing to be carried out under this test program was set out in a proposal from AEA Technology to Cogema Hanford, Inc (Ref 3). The broad scope, as specified by Cogema, is as follows: -

- Expanding the existing fluidic sampling test rig for sampling at $24 \mathrm{ft}, 42 \mathrm{ft}$, and $57 \mathrm{ft}$ "lift" heights.

- Measuring vacuum levels in the sample bottle over the above range of "lift" heights and other system operating parameters.

- Measuring sampling rates (liters/minute sample delivered to the sample bottle) as a function of "lift" height and other system operating parameters. 


\section{NESTED FIXED DEPTH SAMPLER SAMPLE PONT ELEVATION TESTING}

- Measurement of solids weight content and particle size distributions from extracted samples and grab reference samples.

- Assessing sampling performance by comparing a sample's weight percent solids and particle size distributions with grab samples taken at the sample channel inlet for each of the above lift heights.

- Test sampling performance with a 25-30-wt \% sludge simulant for the above "lift"heights by measuring operating parameters and the contents of samples (wt\% solids).

- Preparation of a report detailing the results of the tests. 


\section{Description of the Test Facilities}

\subsection{SAMPLER SYSTEM OPERATION}

\subsubsection{General}

A fluidic sampler consists of two main components, the fluidic Reverse Flow Diverter (RFD) Pump, and the fluidic sampling Tee. Both components are critical to the sampler operation, the pump is used to lift the sample to the Tee and the Tee draws the sample into the sampling bottle. The main elements of a fluidic RFD pump are shown below and consist of:

- The pumping element - a passive fluidic device through which fluid enters the pump from the supply tank. The details of this element are described later

- a charge vessel

- a primary controller for providing the gas pressure and flow conditions in the charge vessel and acting as a barrier between the clean incoming compressed gas and the potentially hazardous liquid

- a secondary controller which handles only clean gas and provides the gas flow to the primary controller as required

Note: In a fluidic sampler a 'sampling tee' takes the place of the delivery tank shown below (see section

2.3).

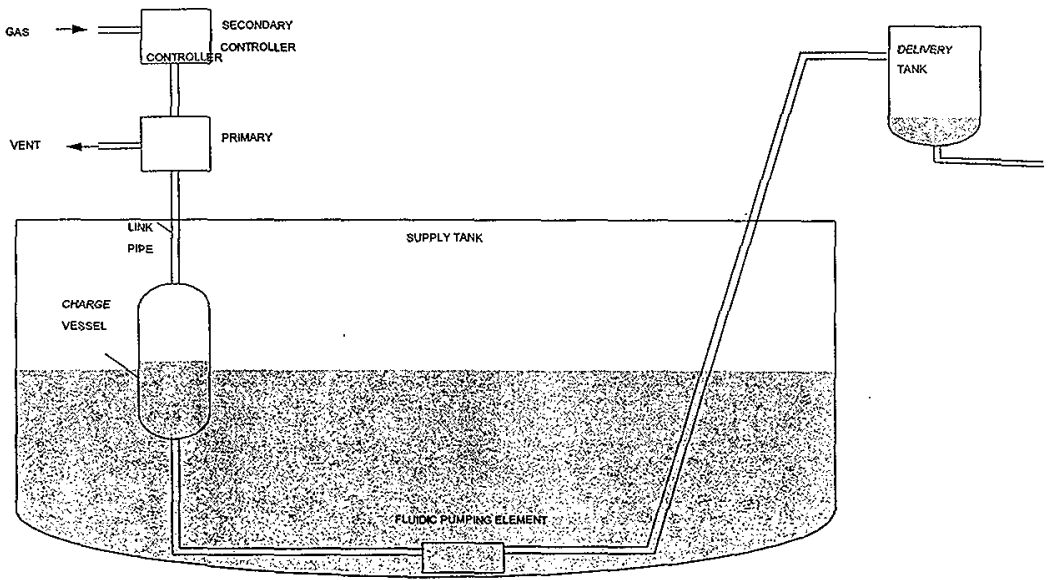

\subsubsection{Cycle Operation}

The rfd pump typically operates in three phases: 

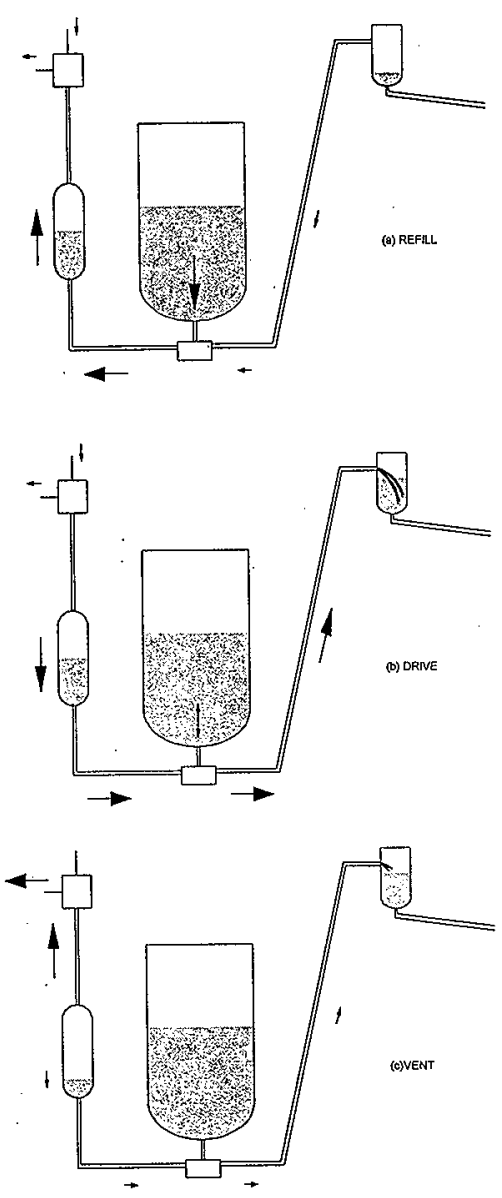

Refill Phase In this phase, liquid from the supply tank enters the charge vessel through the pumping element and the phase continues until the liquid level has reached the top of the charge vessel and enters the air link pipe. When required, a partial vacuum is applied to the charge vessel by the primary controller to augment the filling rate.

Drive Phase In this phase, compressed gas is passed via the primary controller into the charge vessel which forces the liquid through the pumping element and along the delivery pipe into the delivery vessel. This continues until the air-liquid interface reaches the bottom of the charge vessel, at which time the compressed gas supply is terminated. The role of the pumping element in this phase is to entrain further fluid from the supply tank and into the delivery pipe or, at the very least, to minimize the amount of fluid flowing back into the supply tank.

Vent Phase In this, the third and final phase, the compressed gas supply to the pump has ceased and the high-pressure gas in the charge vessel is allowed to escape to vent through the primary controller. The liquid contained in the delivery pipe also tends to fall back into the charge vessel; the amount by which the pipe empties depends on the pump design, the imposed operating frequency, and the type of pump element used. When the pressure in the charge vessel has fallen close to atmospheric pressure, the refill phase recommences and the whole cycle is repeated.

The pump therefore operates in a cyclic manner, delivering intermittent "dollops" of liquid into the delivery vessel.

\subsubsection{Pumping Elements}

The pumping element shown in the figure above is the Reverse Flow Diverter, RFD. The RFD operates like a three-way valve. It consists of two opposing nozzles; a symmetrical design is shown in the figure. 


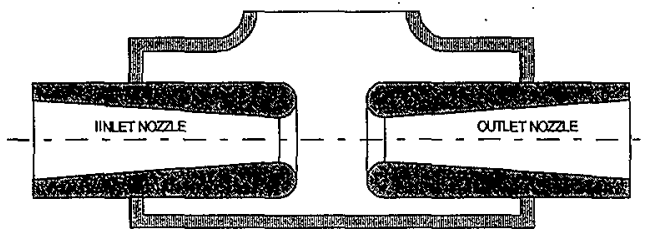

BASIC RFD DESIGN

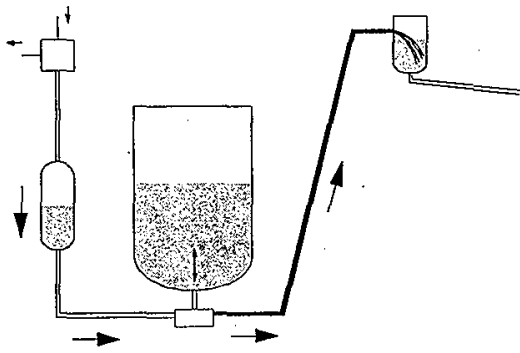

In operation as a pumping element, fluid enters the inlet nozzle during the drive phase, passes across the gap, entraining fluid from the supply tank, and the static pressure is then recovered along the outlet nozzle/diffuser section. Fluid from the supply tank is entrained by the flow emerging from the nozzle, but depending on the pressure in the delivery line a small proportion of the nozzle flow may be fed back into the tank; so called "negative entrainment".

During the refill phase, liquid passes through the inlet nozzle (now acting as a diffuser) and into the charge vessel with only a relatively low resistance to flow produced by the well rounded entry to the diffuser.

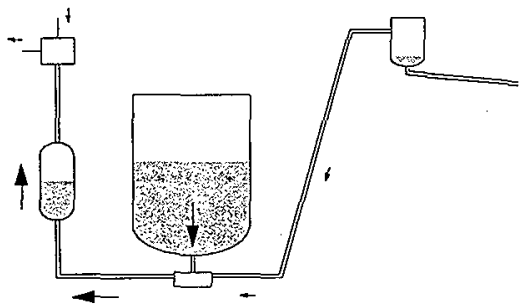

\subsubsection{Primary Controller}




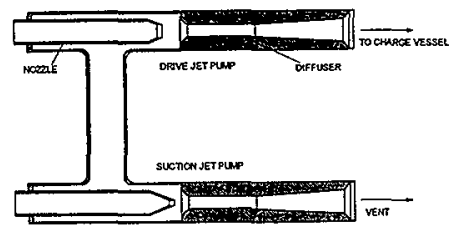

(U) SETPWOP FNR

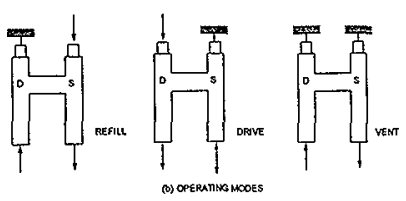

From the preceding paragraphs it can be seen that the requirements of the primary controller are to provide a positive gas flow and pressure to the charge vessel during the drive phase, to allow a vent path for this gas during vent, and then to provide a partial vacuum in the charge vessel during refill.

This is normally accomplished using a jet pump pair, which is shown schematically in the figure together with the modes of operation for the three phases of the pump's cycle.

\subsubsection{Secondary Controller}

The requirements of the secondary controller are to regulate the supply of compressed gas to the "drive" part of the primary controller during the drive phase, to switch off the gas supply during vent, and then to regulate the"suction" phase of the primary controller during refill. This task is often accomplished using conventional solenoid valves, which only need to handle clean gas and are installed in an accessible position so that maintenance can be performed.

The other function of the secondary controller is to control the duration for which the gas is supplied to the primary controller, i.e. to set the phase times of the cycle. The method of achieving this is dependent on the type of pumping element used as outlined below.

The RFD pump system is normally designed with the charge vessel volume several times greater than the volume of the delivery pipe. Consequently at the end of the refill phase, the delivery pipe has emptied (down to the level of the liquid in the supply tank - see Fig. Pg. 7) and the level of liquid in the charge vessel has risen in the air link pipe to a level compatible with the amount of vacuum supplied by the primary controller. The system is then in hydrostatic equilibrium and the liquid flowrate is zero everywhere within the pump. This condition represents a datum from which each cycle of the pump conmences and is necessary to avoid cycle instability and which could result in "overblow".

*During the drive (or vent) phase, if the air liquid interface passes beyond the base of the charge vessel, the compressed gas will be blown into the supply and delivery tanks which can lead to over-pressurization of these vessels and the creation of airborne aerosols. This is a condition known as 'overblow'. 


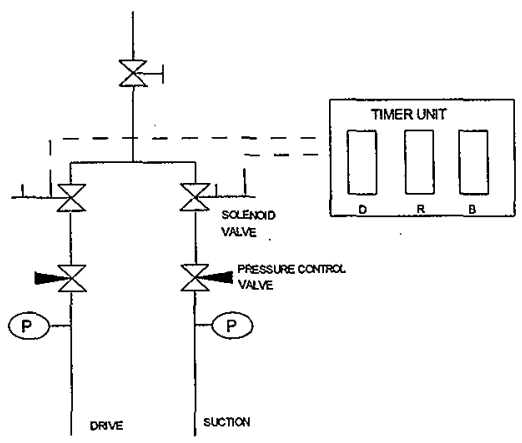

(a) ELECTRONIC TIMER SYSTEM (OPEN LOOP)

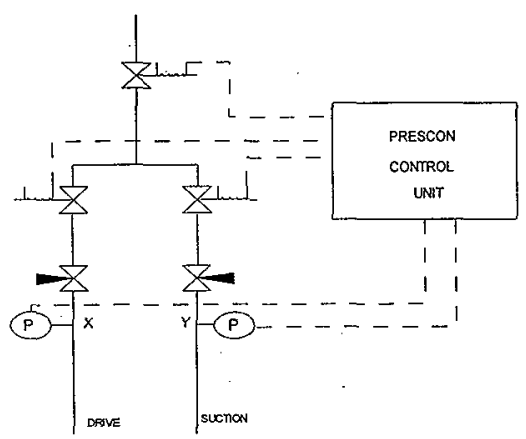

(b) PRESCON SYSTEM (CLOSEO LOOP)
The phase sequencing of this type of pump can therefore be achieved in an open loop manner with electronic timers where the time of each phase of the pump is predetermined from experiment or theoretical predictions.

In a pumping system, irrespective of the type of pumping element employed, the time taken to refill the charge vessel increases as the level of liquid in the supply tank falls. The drawback to the use of electronic timers therefore is that in order to ensure reaching the datum position, the time for the refill phase must be set such that the charge vessel will fill even at the lowest supply tank level. This leads to very inefficient operation.

A solution to the problem is provided by the Prescon (PRESsure CONtrol) method which makes use of the observation that there is a characteristic pressure change as measured at the point $X$ when the charge vessel becomes full. By detecting this pressure change, it is possible to start the drive phase immediately when the charge vessel is full and so operate at optimum efficiency. This therefore provides a reliable, nonintrusive, closed-loop control method. In addition, the occurrence of overblow can be detected by analyzing the pressure measured at point $Y$.

\subsection{TEST RIG DESCRIPTION}

The Test Rig used for the sample point elevation tests incorporated a single RFD fluidic pump connected to a specially designed sampling tee instalted in the discharge pipework.

The fluidic sample pump comprised a cylindrical stainless steel charge vessel 64" (flange to flange) $\times 4$ " internal diameter, connected to a stainless steel RFD pumping element by bolted flanged pipe connections. All pipework was sized at 1 " internal diameter. The apertures in the jet nozzles in the rfd were sized at $5.7 \mathrm{~mm}$ diameter. The charge vessel was connected via 1 " braided flexible pvc hose to a single primary controller. The fluidic pump assembly was mounted in a steel supply tank, 16" in diameter by 62" high, of 50gallon capacity. This capacity ensured that sampling does not deplete tank volume by more than $5-10 \%$. 


\section{NESTED FIXED DEPTH SAMPLER SAMPLE POINT ELEVATION TESTING}

In order to provide adequate agitation to maintain solid simulants in suspension, a pneumatically driven mechanical agitator ("Mix-Mor' model GA-11) was installed in the supply tank. The agitator consists of a single air driven shaft with a 12 " diameter 3 bladed propeller type impeller at the end. The agitator was installed so the impeller was situated approximately 2 " above the tank base below the sample pump RFD. Speed of the impeller was regulated by the flow of compressed air. The speed of the agitator could not be directly measured but was set to as high a speed as possible without causing excessive turbulence or splashing.

The primary controller consisted of a single jet pump pair operating on a compressed air supply provided by a $82.5 \mathrm{cfm}$ portable diesel powered compressor. Airflow to the jet pump pair was controlled by a secondary controller or electronic pressure control unit (PRESCON). Primary and secondary controllers were securely mounted on a scaffold tube framework adjacent to the samplers.

The RFD was connected, via a 1"i.d. flexible braided pvc hose, to the sample tee. For the purposes of this sequence of tests, the sample tee was fixed to a backing board, which was in turn mounted to a crane 'basket'. The crane basket could be winched up over the full range of heights required for this testing using a 40-ton capacity 'Coles' crane and trained operator rented for the purpose. A 1"i.d. returns line was attached from the sample tee to the supply tank to return the simulant to the tank, avoiding depletion and ensuring continuous operation. In order for sampling to take place, the liquid in the delivery and return lines must briefly siphon back through the sample tee at the end of the drive phase. For this to occur the quantity of liquid in the delivery line must be greater than that in the return line. To ensure this it is necessary to provide a 'siphon break' in the return line. To provide the 'siphon break' necessary for effective sampler operation in the test rig, the return line was enlarged to 2 " in diameter approximately $8 \mathrm{ft}$ below the tee. 


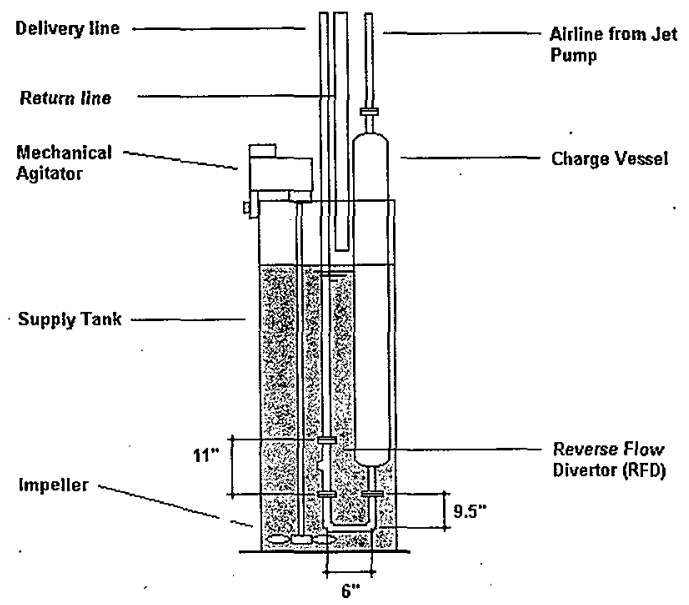

RFD PUMP \& SUPPLY TANK ASSEMBLY

The RFD pump assembly is shown in the above sketch. The sample tee was fitted with a single sample needle $1 / 8$ in. in diameter. In order for sampling to take place, the operator in the crane basket placed the sample bottle, fitted with a suitable lid and seal, over the needle. The sample tee and flexible hoses were all constructed from transparent polymer material allowing the operation of the sampler to be clearly observed.

To ensure correct sampler operation and maintain rig conditions as representative of field conditions as possible, the flexible supply and return lines to and from the sampler have to be kept as straight as possible. Therefore, these lines were both spliced, each at 2 locations, so that excess lengths of hose could be decoupled to maintain relatively straight lengths of hose from the sample pump to the tee at all elevations.

The sketch below shows a diagrammatic representation of the overall test setup. 

NESTED FIXED DEPTH SAMPLER SAMPLE POINT ELEVATION TESTING

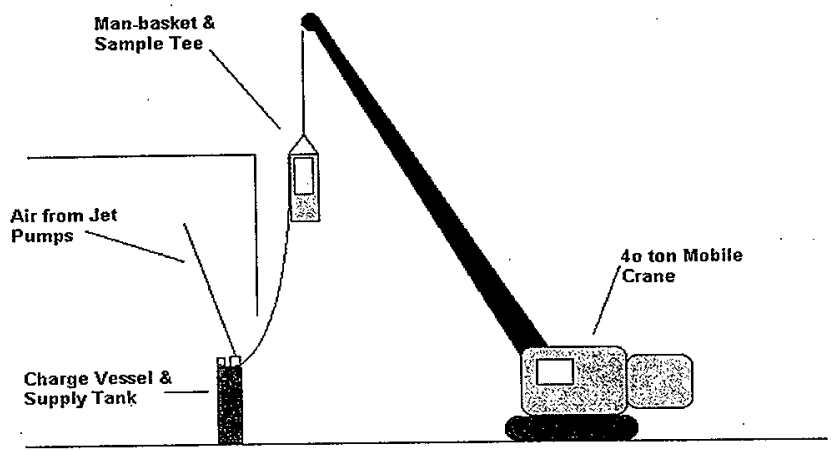

OVERALL TEST SET UP FOR SAMPLE POINT ELEVATION TESTING 
AEA TECHNOLOGY ENGINEERING SERVICES INC NESTED FIXED DEPTH SAMPLER SAMPLE POINT ELEVATION TESTING

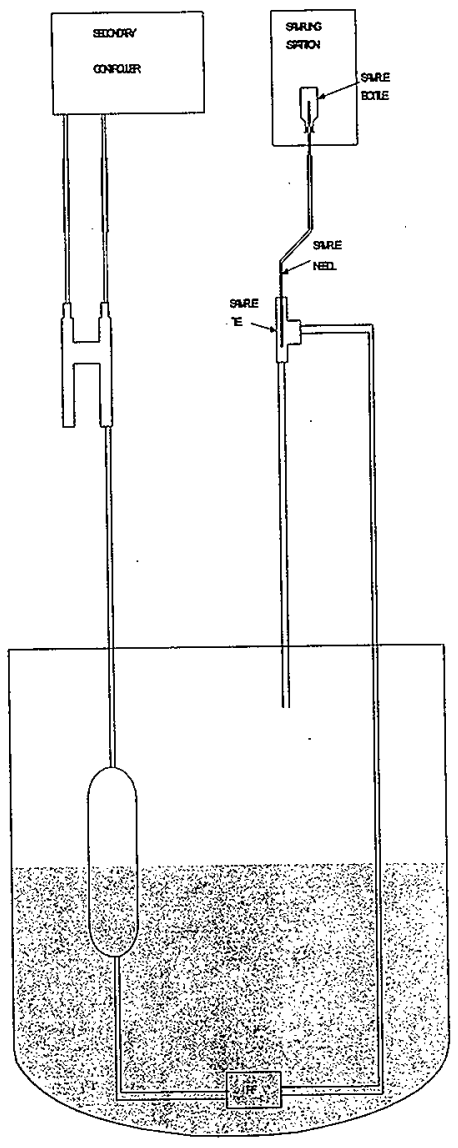

\subsection{SAMPLING PROCEDURE}

The diagram opposite is a schematic representation of the sampler test rig. The rig comprises an RFD fluidic pump connected to a single specially designed sampling tee installed in the discharge pipework which delivers a sample of the liquid through a sample needle to the sample bottle. The flow from a fluidic pump is intermittent; i.e. there is a delivery of liquid followed by a period where the pump is refilling. This intermittent flow is used to make the sampling system operate The operation of the 'sampling tee' and procedure for obtaining primary samples is described below. 

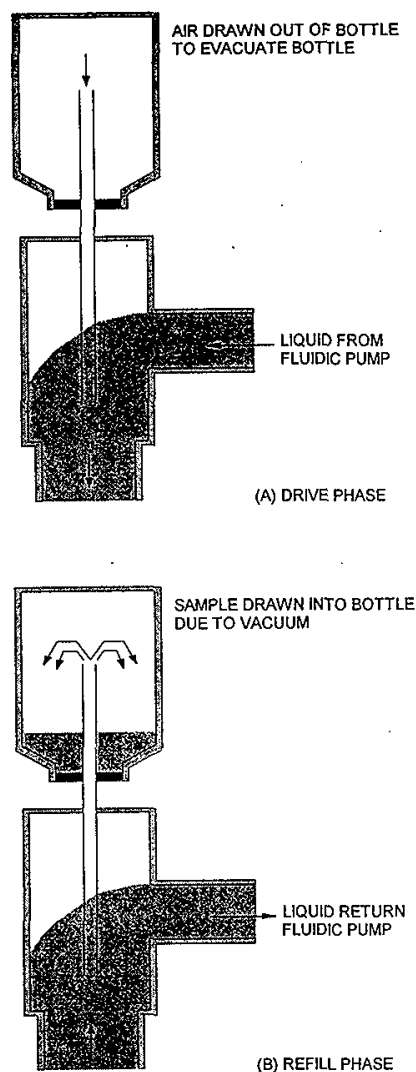

When the pump is delivering liquid along the delivery line the liquid will have some velocity. As the liquid passes the end of the sampling needle there is a venturi effect which draws air down the needle from a sample bottle on the other end of the needle (usually plastic with a rubber seal on the other end)

As the delivery pulse from the pump ends, the liquid velocity past the needle decreases and the partial vacuum in the bottle draws liquid back into the bottle

A sample is normally collected over a number of cycles in this manner; the length of the needle penetrating into the bottle governs the total amount of sample collected.

A feature of the the fluidic sampler, when properly designed and operated, is that when no sample bottle is on the needle, it should not be possible for liquid to pass up through the needle. If a sample pump is run without a bottle, for example to purge the sample lines, the liquid flow should draw a small amount of air down through the needle into the tank. Without a bottle to hold suction, there is no driving force for liquid flow up through the needle. However this 'fail-safe' condition relies on correct design of the sample tee, and regulation of the drive pressure. 


\section{NESTED FIXED DEPTH SAMPLER SAMPLE POINT ELEVATION TESTING}

\subsection{TEST SIMULANTS}

The sampling performance testing used water/sand siurry and Kaolin/water slurry simulants. The specification for the water/sand simulant was provided in Ref 2 , It was required that the sand simulant should have a particulate size distribution approximately as shown in Table 1.

The sand simulant was prepared by blending 'Min-U-Sil', a proprietary ground silica product with particle size in the $<50 \mu \mathrm{m}$ range, with selected commercial horticultural sands. The calculated particle size distribution of the solid simulant based on a sieve analysis is as shown below in Table 2 .

\subsection{TEST MEASUREMENTS}

\subsubsection{Measurement Methods}

Secondary samples for comparison purposes were taken from the sampler feed tank adjacent to the RFD using a simple 'grab' sampling technique derived from ASTM E300-92 'Standard Practice for Sampling Industrial Chemicals'.

The grab samples were obtained using a $40 \mathrm{ml}$ sample bottle attached to a plastic tube, positioned such that with the tube touching the base of the tank the bottle would be at the height of the sampler RFD port. The sample bottle was sealed with a stopper attached to a length of string, before being lowered into the tank. When the bottle was at the rfd height, the stopper was removed and the bottle allowed to fill with simulant. The bottle was then catefully withdrawn and a screw fitting lid placed on it. The bottle was then labeled and dispatched to the laboratory for analysis.

The analysis of samples and measurement of operating parameters for the conceptual nested, fixed-depth sampling system was carried out using the following methods:

- Particle size distribution - Microscopic examination as per ASTMF312.

- Solids weight $\%$ content - Filtration and evaporation at 105 C per EPA 160.3.

- Vacuum - 'U.S. Gauge' V500 dial gauge

- System pressures - $\quad$ 'FTS' model SSP11 installed electrical transducers

\subsubsection{Measurement Accuracy}

\subsubsection{Particle Size Distribution}

The nominal accuracy of the ASTM method used to determine particle size distribution is reported by the analysis laboratory to be of the order of $+1-20 \%$. However due to the nature of the simulant used in these particular tests, the actual accuracy achieved is believed to be substantially less than this. The following factors are the major contributors to the reduced accuracy levels achieved:-

- Difficulty was encountered in ensuring representative samples for analysis could be extracted from the main body of the sample. Although samples were agitated by hand prior to sample extraction, the high rate at which the larger particles resettled meant that they were not adequately represented in the analysis sample. Mechanical agitation of the main sample during analysis sample extraction was impractical and would introduce another source of variability/error.

- The very high proportion of fine particles in the sample caused significant 'masking' of larger particles during microscopic examination. Significant dilution of the sample was required to overcome this problem leading to a substantial increase in the error band. 
In the estimation of the analysis laboratory final error bands encountered in these tests were substantial possibly in excess of $100 \%$.

\subsubsection{Weight \% Solids}

The nominal accuracy of the method used to determine weight percent solids is reported by the analysis laboratory to be of the order of $+1-5 \%$.

As in the method used for psd the accuracy of the analysis method was also degraded (though to a much lesser degree) by settling of solids during sampling (it is estimated that this would increase the error band by less than $1 \%$ ),

\subsubsection{Vacuum}

The accuracy of the vacuum gauge used in the tests is reported by the distributor to be of the order of $+/-$ $3 \%$.

\subsubsection{System Pressures}

The tolerance on the drive / suction pressure is set by an engineer variable. The default is $+/ .15 \%$ but has an adjustment range of 0 to $20 \%$. The accuracy of the readings is $0.1 \%$. 


\section{Test Methodology}

\subsection{GENERAL}

Tests were conducted at each of the 3 elevations specified, i.e. $24 \mathrm{ft}, 42 \mathrm{ft} \& 57 \mathrm{ft}$. The test rig was manned by 3 operators, one of whom was located in the crane basket during testing to take samples, measure vacuum pressure and monitor conditions at the sample needle. Prior to commencement of simulant testing, the supply tank was filled with water and operation was tested by observation and taking samples at each of the 3 specified test elevations.

\subsection{CONTROLLER CALIBRATION}

Initial testing was conducted with water simulant at 3 heights to determine lowest drive pressure for sampling and highest drive pressure before 'spitting' i.e. discharge of liquid from the sample needle without a sample bottle in place.

The controller was set to operate with the following settings:-

$(\operatorname{Ref} 1 \mathrm{bar}=14.50 \mathrm{lb} / \mathrm{in} 2)$

\section{Controller Settings}

Suction Pressure

Drive Pressure

Drive Time

Suction Time

Valve Settling Time

\section{7' 'Test with Water}

Test Results 57'

Drive Pressure

$\begin{array}{ll}1.00 & \text { bar } \\ 2.00 & \text { bar } \\ 2.50 & \text { bar } \\ 2.75 & \text { bar } \\ 3.00 & \text { bar }\end{array}$

\section{2' Test with Water}

Test Results 42'

Drive Pressure

$$
\begin{aligned}
& 1.50 \\
& 2.00 \\
& 2.25 \\
& 2.50 \\
& 2.75 \\
& 3.00
\end{aligned}
$$

\section{4' Test with Water}

Test Results 24'
Drive Pressure
Result

$\begin{array}{ll}\text { bar } & \text { No delivery } \\ \text { bar } & \text { Liquid reached } T \text { but no delivery } \\ \text { bar } & \text { Delivery received . } \\ \text { bar } & \text { No spitting at needle } \\ \text { bar } & \text { Spitting at needle }\end{array}$

Result

bar No delivery

bar Liquid reached $\mathrm{T}$ but no delivery

bar Small sample delivered

bar Delivery received

bar Very slight spitting at needle

bar Spitting at needle 


$\begin{array}{lll}1.00 & \text { bar } & \text { Small delivery } \\ 1.25 & \text { bar } & \text { Good delivery } \\ 1.50 & \text { bar } & \text { No spitting } \\ 1.75 & \text { bar } & \text { No spitting } \\ 2.00 & \text { bar } & \text { Slight spitting at needle }\end{array}$

\subsection{WT\% SAND SIMULANT TESTS}

The purpose of this test was to demonstrate that sampling could take place at the three specified heights, quantify the volume of the sample and compare the sample to a "grab" sample taken at the same time as the sample was delivered to the bottle. Prior to commencement of testing, a predetermined weight of dry sand simulant (see table 2 for particle size distribution) was added to the water in the supply tank. The simulant was maintained in suspension by activation of the impeller/mixer in the supply tank.

At each of the $24 \mathrm{ft}$ and $42 \mathrm{ft}$ elevations, a $500 \mathrm{ml}$ sample bottle was placed on the sample needle and the sample pump was run for a preset total of 10 cycles. At the 57 -ft elevation, a $500 \mathrm{ml}$ sample bottle was placed on the sample needle and the sample pump was cycled until the bottle had been filled. The total number of cycles required to fill the bottle was then recorded.

Controller settings were as follows:

\section{4' Test with 2 wt $\%$ Silica in Water}

Controller Settings

Suction Pressure

Drive Pressure

3.00 bar

Drive Time

1.5 bar

Suction Time

$20.00 \quad \mathrm{Sec}$

Valve Settling Time

$60.00 \quad \mathrm{Sec}$

Approx. Cycle Time

$10.00 \quad \mathrm{Sec}$

$81 \quad$ Sec

The test ran for 10 cycles plus 2 cycles so the vacuum at the needle could be measured.

\section{2' Test with 2 wt $\%$ Silica in Water}

Controller Settings

$\begin{array}{lll}\text { Suction Pressure } & 3.00 & \text { bar } \\ \text { Drive Pressure } & 2.75 & \text { bar } \\ \text { Drive Time } & 25.00 & \text { Sec } \\ \text { Suction Time } & 60.00 & \text { Sec } \\ \text { Valve Settling Time } & 10.00 & \text { Sec } \\ \text { Approx. Cycle Time } & 86 & \text { Sec }\end{array}$

The test ran for 10 cycles plus 2 cycles so the vacuum at the needle could be measured.

\section{7' Test with 2 wt $\%$ Silica in Water}

Controller Settings

Suction Pressure $\quad 3.00 \quad$ bar 


\section{NESTED FIXED DEPTH SAMPLER SAMPLE POINT ELEVATION TESTING}

Drive Pressure

Drive Time

Suction Time

Valve Settling Time

Approx. Cycle Time

$\begin{array}{ll}2.75 & \text { bar } \\ 25.00 & \text { Sec } \\ 60.00 & \text { Sec } \\ 10.00 & \text { Sec } \\ 86 & \text { Sec }\end{array}$

Note: At this stage the test was stopped due to inconsistent performance of the sampler. A blockage was suspected, and in order to investigate the problem the sampler pump was removed and the supply tank emptied. Investigation revealed the presence of fragments of a hard scale type mineral formation in the charge vessel, RFD and connecting pipework. The fragments varied in size up to approximately $3 / 4$ " across, and were identified as residue from a previous unrelated test program. The pipework and charge vessel were cleaned and flushed with water, then reassembled.

A new batch of simulant was mixed and fed in to the supply tank. Testing was then recommenced. Following the detection of the blockage the controller settings were reset for satisfactory operation as follows:

\section{4, Test with 2wt\% Silica in Water (2)}

Controller Sẹttings

$\begin{array}{lll}\text { Suction Pressure } & 3.00 & \text { bar } \\ \text { Drive Pressure } & 1.75 & \text { bar } \\ \text { Drive Time } & 25.00 & \mathrm{Sec} \\ \text { Suction Time } & 60.00 & \mathrm{Sec} \\ \text { Valve Settling Time } & 10.00 & \mathrm{Sec} \\ \text { Approx. Cycle Time } & 86 & \mathrm{Sec}\end{array}$

The test ran for 10 cycles plus 2 cycles so the vacuum at the needle could be measured.

\section{2' Test with 2 wt\% Silica in Water (2)}

Controller Settings

$\begin{array}{lll}\text { Suction Pressure } & 3.00 & \text { bar } \\ \text { Drive Pressure } & 2.75 & \text { bar } \\ \text { Drive Time } & 25.00 & \text { Sec } \\ \text { Suction Time } & 60.00 & \text { Sec } \\ \text { Valve Settling Time } & 10.00 & \text { Sec } \\ \text { Approx. Cycle Time } & 86 & \text { Sec }\end{array}$

The test ran for 10 cycles plus 2 cycles so the vacuum at the needle could be measured.

\section{7' Test with $2 w t \%$ Silica in Water (2)}

Controller Settings

$\begin{array}{lll}\text { Suction Pressure } & 3.00 & \text { bar } \\ \text { Drive Pressure } & 2.75 & \text { bar } \\ \text { Drive Time } & 25.00 & \text { Sec } \\ \text { Suction Time } & 60.00 & \text { Sec } \\ \text { Valve Settling Time } & 10.00 & \text { Sec } \\ \text { Approx. Cycle Time } & 86 & \text { Sec }\end{array}$


A $500 \mathrm{ml}$ sample bottle was filled in 25 cycles and a further 2 cycles were performed so the needle vacuum could be measured.

\subsection{WT\% SAND SIMULANT TESTS}

The purpose of this test was to demonstrate that sampling could take place at the three specified heights, quantify the volume of the sample and compare the sample to a "grab" sample taken at the same time as the sample was delivered to the bottle. Prior to commencement of testing, a predetermined weight of dry sand simulant simulant (see table 2 for particle size distribution) was added to the simulant in the supply tank. The simulant was maintained in suspension by activation of the impeller/mixer in the supply tank.

At each of the $24 \mathrm{ft}$ and $42 \mathrm{ft}$ elevations, a $500 \mathrm{ml}$ sample bottle was placed on the sample needle and the sample pump was run for a preset total of 10 cycles. At the $57 \mathrm{ft}$ elevation, a $500 \mathrm{ml}$ sample bottle was placed on the sample needle and the sample pump was cycled until the bottle had been filled. The total number of cycles required to fill the bottle was then recorded.

Controller settings were as follows:

\section{7' Test with 10wt\% Silica in Water}

Controller Settings

$\begin{array}{lll}\text { Suction Pressure } & 3.00 & \text { bar } \\ \text { Drive Pressure } & 2.75 & \text { bar } \\ \text { Drive Time } & 25.00 & \text { Sec } \\ \text { Suction Time } & 60.00 & \text { Sec } \\ \text { Valve Settling Time } & 10.00 & \text { Sec } \\ \text { Approx. Cycle Time } & 86 & \text { Sec }\end{array}$

A $500 \mathrm{ml}$ sample bottle was filled in 24 cycles and a further 2 cycles were performed so the needle vacuum could be measured.

\section{2' Test with $10 \mathrm{wt} \%$ Silica in Water}

Controller Settings

$\begin{array}{lll}\text { Suction Pressure } & 3.00 & \text { bar } \\ \text { Drive Pressure } & 2.75 & \text { bar } \\ \text { Drive Time } & 25.00 & \text { Sec } \\ \text { Suction Time } & 60.00 & \text { Sec } \\ \text { Valve Settling Time } & 10.00 & \text { Sec } \\ \text { Approx. Cycle Time } & 86 & \text { Sec }\end{array}$

The test ran for 10 cycles pius 2 cycles so the vacuum at the needle could be measured.

\section{4' Test with 10wt\% Silica in Water}

Controller Settings

Suction Pressure $\quad 3.00 \quad$ bar

Drive Pressure $\quad 1.75 \quad$ bar

Drive Time $\quad 25.00 \quad \mathrm{Sec}$

Suction Time $\quad 60.00 \quad \mathrm{Sec}$ 


\section{NESTED FIXED DEPTH SAMPLER SAMPLE POINT ELEVATION TESTING}

$\begin{array}{lll}\text { Valve Settling Time } & 10.00 & \text { Sec } \\ \text { Approx. Cycle Time } & 86 & \text { Sec }\end{array}$

The test ran for 10 cycles plus 2 cycles so the vacuum at the needle could be measured.

\subsection{KAOLIN SIMULANT TESTS}

Upon completion of testing using the sand simulant, the simulant was fully mixed in the supply tank using the mechanical mixer and then transferred to a stock tank using a sandpiper pump connected to the drain spigot at the base of the tank. The supply tank was then refilled with a pre-mixed kaolin/water slurry. The mechanical mixer was then reactivated and concentrated clay slurry was added until the desired wt $\%$ value of approximately $25 \mathrm{wt} \%$ was achieved. Solids content was initially estimated using a hand held SG meter and a grab sample was also taken for verification by laboratory analysis to determine wt\% solids.

Shortly after sampler operation was commenced, it became evident that the sampler rfd had become blocked which was preventing the sampler charge vessel from filling (the kaolin/water slurry placed in the supply tank had been used in earlier testing work and had become inadvertently contaminated with zeolite without detection). The sampler was removed from the supply tank and dismantled to remove the blockage. The sampler was then flushed with water. A fine fabric mesh was placed over the RFD inlet to filter out the Zeolite. The Sampler was re started but again failed to fill. After removal it was found that the fabric mesh filter was too fine, and had consequently become choked. A coarse filter of $3 / 16$ in. wire mesh was fitted, and the sampler was re installed and restarted, performing satisfactorily for the remainder of the tests.

After the test rig was reassembled the crane basket was taken up to the $57 \mathrm{ft}$ elevation. At the $57 \mathrm{ft}$ elevation, a $500 \mathrm{ml}$ sample bottle was placed on the sample needle and the sample pump was cycled until the bottle had been filled. The total number of cycles required to fill the bottle was then recorded.

\section{7' Test with Clay in Water}

Controller Settings

$\begin{array}{lll}\text { Suction Pressure } & 3.00 & \text { bar } \\ \text { Drive Pressure } & 2.75 & \text { bar } \\ \text { Drive Time } & 25.00 & \text { Sec } \\ \text { Suction Time } & 60.00 & \text { Sec } \\ \text { Valve Settling Time } & 10.00 & \text { Sec } \\ \text { Approx. Cycle Time } & 86 & \text { Sec }\end{array}$

A $500 \mathrm{ml}$ sample bottle was filled in 24 cycles and a further 2 cycles were performed so the needle vacuum could be measured. 


\section{Test Results}

\subsection{CONTROLLER CALIBRATION}

Tests with water were conducted to investigate the control settings required to achieve satisfactory sampler operation over the range of operating heights, in particular the influence of drive pressure. Too low a drive pressure will not deliver a sample at the needle. Too high a drive pressure may lead to 'spitting' (i.e.discharge of simulant through the needle without a sample bottle in place).

It was found that the 'acceptable range of drive pressure over which satisfactory operation was achieved was approximately 0.75 bar at $24 \mathrm{ft}$ elevation reducing to approximately 0.5 bar at $57 \mathrm{ft}$ elevation. A good delivery was achieved at 2.50 bar at $42 \mathrm{ft}$ and $57 \mathrm{ft}$, but the required drive pressure was found to be much lower (1.25 bar) at $24 \mathrm{ft}$.

\subsection{SILICA SIMULANT TESTS}

The results of the tests carried out using the $1-2 \mathrm{wt} \%$, and $10-15 \mathrm{wt} \%$ silica simulants are presented in Tables 3-8.

Note: Due to the contamination problems encountered during the first run with 1-2 wt \% simulant the results of these tests are assumed to be void and are not presented.

Two sets of tests were carried out on each of the needle and grab samples as described in section 2.5, namely;

Particle size distribution Microscopic examination as per ASTM F312.

Solids wt\% content Filtration and evaporation at $105 \mathrm{C}$ per EPA 160.3 .

Regarding the analysis of particle size distribution, it is apparent that analysis has been ineffective in determining the comparative particle size distribution of the samples. This can be attributed to a number of factors, principally:-

- The simulant(s) specified for the determination of sample variability contain a very high proportion of very small particles $(94 \%<50 \mu \mathrm{m})$ which will make it very difficult to highlight any differences in sample constituents by any analysis method.

- The ASTM method used involves sampling, filtration and microscopic examination counting) of the particulate. It is apparent that this method is not well suited to examination of samples containing very large proportions of extremely small particles. The very high proportion of fine particles in the sample caused significant 'masking' of larger particles during microscopic examination. Significant dilution of the sample was required to overcome this problem leading to a substantial increase in the error band.

- Due to the presence of high proportions of small particles, the simulant solutions are highly opaque, making the use of any alternative particle size determination method (such as laser diffraction) difficult without significant dilution of the sample (which would further corrupt results).

The results of the particle size analysis must therefore be viewed with extreme caution as it is suspected that it does not provide a reliable method of assessing sampler performance. For example, it would appear from examination of the analysis that needle samples generally contained proportionally fewer of the larger particles than the grab samples, however visual examination of the needle samples before analysis did show the presence of considerable numbers of particles in the larger range. The analysis laboratory 


\section{AEA TECHNOLOGY ENGINEERING SERVICES INC \\ NESTED FIXED DEPTH SAMPLER SAMPLE POINT ELEVATION TESTING}

INF-3864, REV. 0

have reported an accuracy of $+/-25 \%$ for the method used, however it is suspected that due to the conditions described above the accuracy of the tests is likely to be substantially lower.

From tables 3-8, variation of wt \% measurements between needle and mean of grab samples for run 2 is $+5.1 \%,-15.1 \%,+24.9 \%$ at $24 \mathrm{ft}, 42 \mathrm{ft}$ and $57 \mathrm{ft}$ respectively. Corresponding values for run 3 are $-4.4 \%$, $+7.4 \%$, and $+30.3 \%$. From these results the following observations can be made:-

- Correlation between needle samples and grab samples is consistent with the system design requirement of $+1-5 \%$ at the $24 \mathrm{ft}$ level for both simulant concentrations.

- Correlation between needle and grab samples diminishes at $42 \mathrm{ft}$ level and further at diminishes at $57 \mathrm{ft}$ level.

- There is an apparent trend of increased solids content in needle samples as sampling elevation increases.

Again these results must be viewed with caution, as :-

1. The number of measurements taken overall is considered too small to establish reliable statistical trends.

2. Accuracy of the wt\% analysis of the silica simulant samples are likely to be less than that stated by the analysis laboratory and presented in section 2.5 .2 . The analysis laboratory has reported that wt\%. measurements were made on sub-samples taken form the $40 \mathrm{ml} \& 500 \mathrm{ml}$ samples submitted. This will increase error bands by measuring extremely small masses of solids from a given sample.

3. The results of the wt\% analysis also show considerable variability, particularly across grab samples taken from the supply tank. As thorough and uniform mixing of the simulant material in the supply tank cannot be guaranteed, significant variability between grab samples is to be expected. Contamination of the grab sample by simulant at higher levels in the tank as it is withdrawn will also be a contributing factor.

In each of the $57 \mathrm{ft}$ elevation tests it was found that it took approximately 25 cycles to fill the $500 \mathrm{ml}$ sample bottle over a total time period of approximately 35 minutes in each case.

\subsection{KAOLIN SIMULANT TESTS}

A single needle sample of $25-30 \mathrm{wt} \%$ kaolin simulant was taken from the sample needle at $57 \mathrm{ft}$ along with a number of corresponding grab samples. A total of 24 cycles was required to fill the sample bottle, over a period of approximately 35 minutes.

Particle size distribution analysis of the kaolin simulant is not practical due to the nature of the material. However $w t \%$ analysis revealed a very good correlation between the needle sample and the grab samples, the needle sample being within $3 \%$ of the grab sample mean. Due to the much greater homogeneity of the kaolin simulant it is likely that the effect of errors caused by sampling and analysis methods are greatly reduced.

The greater homogeneity of the simulant in the supply tank leads also to reduced variability across the grab samples. In particular the effect of contamination of the grab sample during removal by material at higher level would be less significant. This is confirmed by the much reduced standard deviation in comparison to the silica samples. 


\subsection{VACUUM TESTS}

Sample needle vacuum was measured by attaching a dial type vacuum gauge to the sample needle during cycling in place of a sample bottle. Visual readings of vacuum level read from the gauge were manually recorded at timed 2 second intervals during the drive and vent phases.

Using this data an approximate graph showing the apparent variation of vacuum at the needle with time has been sketched and is shown below.

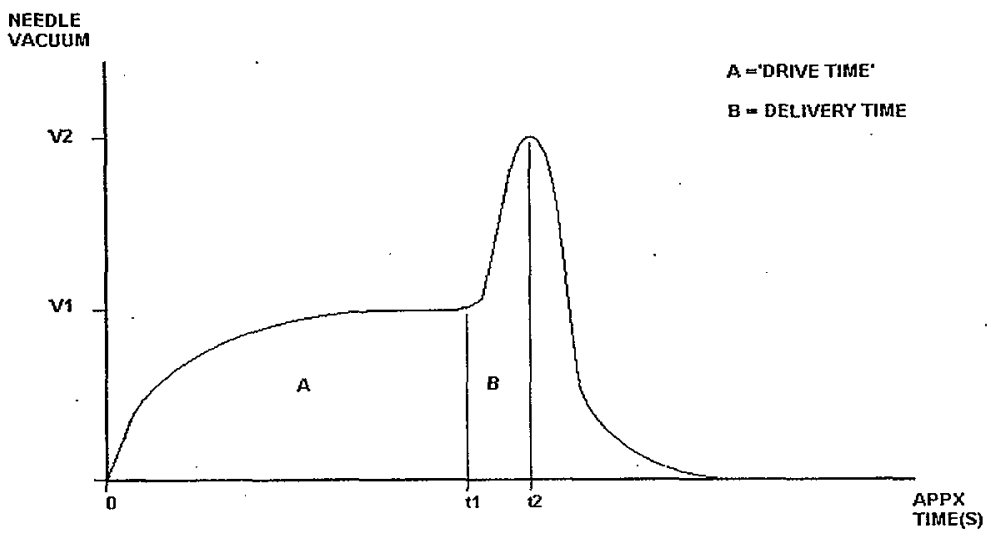

APPROXIMATE CURVE OF SAMPLE NEEDLE VACUUM VARIATION WITH TIME

The 'drive time' referred to is the time when the 'dollop' of simulant passes through the sample tee. The delivery time is the time immediately following the end of the drive phase of the rfo pump, when the delivery of a sample into the sample bottle takes place. ' $\mathrm{V} 1$ ' is the steady state vacuum pressure reached during the drive phase. ' $\mathrm{V} 2$ ' is the peak vacuum pressure recorded during sampling. Time ' $\mathrm{t} 1$ ' is variable, see the specific control parameters and drive times given in section 3.0. The delivery time ( $t 2-t 1)$ was recorded as approximately 2 seconds.

The results of the vacuum tests are recorded below :-

$\begin{array}{lccc}\text { Simulant } & \text { Elevation } & \text { V1 (in. Hg) } & \text { V2 (in. Hg) } \\ 1-2 w t \% \text { Silica } & 24 \mathrm{ft} & 4.0-5.0 & 7.0-7.5 \\ & 42 \mathrm{ft} & 4.0-5.0 & 7.0-7.5 \\ & 57 \mathrm{ft} & 4.0-5.0 & 7.0-7.5 \\ & & & 7.0-7.5 \\ 10-15 \mathrm{wt} \% \text { Silica } & 24 \mathrm{ft} & 4.0-5.0 & 7.0-7.5 \\ & 42 \mathrm{ft} & 4.0-5.0 & 7.0-7.5\end{array}$


NOTE: Precise readings of $\mathrm{Vl}$ and $\mathrm{V} 2$ are not given as the vacuum gauge readings were observed to fluctuate in the range shown. 


\section{Conclusions}

\subsection{CONTROLLER CALIBRATION}

Investigation of the required control parameters at different heights suggests that it is necessary to modify control parameters to achieve consistent sampling performance when sampling from a wide range of RFD to needle separations. However the onset of problems such as needle 'spitting' is also influenced by factors other than this separation, in particular the geometry of the sample tee.

It can be concluded therefore that the effect of factors such as RFD to needle separation and sample tee geometry on the performance of the proposed nested fixed depth fluidic sampler should be the subject of further investigation to allow these factors to be properly considered in the design.

\subsection{SAND SIMULANT TESTS}

The principal conclusions to be drawn from the results of the sand simulant tests are:-

- $500 \mathrm{ml}$ silica simulant samples can readily be generated at each of the specified elevations

- Correlation between needle samples and grab samples is consistent with the system design requirement of $+1-5 \%$ at the $24 \mathrm{ft}$ level for both simulant concentrations.

- Due to the nature of the specified simulant and the limitations of the particle size analysis methods available it was not possible to establish reliable data on variation of sample composition with variations in $R F D$ to needle separation.

- Standard deviation values indicate that overall solids content of grab samples are subject to significant variability.

- There is an apparent trend for needle samples taken at higher levels to contain higher proportions of solids. However the number of measurements made is not sufficient to reliably establish statistical trends.

If the presence of increased solids in the samples taken at higher levels is a genuine trend, it may be attributable to a phenomenon known as 'slippage'. This occurs when the settlement velocity of the simulant particles is significant relative to the velocity of flow in the supply line. It results in progressive concentration of particulate in the supply line and consequently in the sample delivered through the needle. This phenomenon is recognized in fluidics and is controlled by the design of the component geometry to achieve optimum flow velocities and render slippage effects insignificant. The significance of this effects in these results is due to the fact that the test rig components were not purpose designed to form a correctly 'balanced' system. In the prototype sampler design slippage effects will be rendered far less significant by proper design.

\subsection{KAOLIN SIMULANT TESTS}

The principal conclusions to be drawn from the results of the kaolin simulant tests are:-

- $500 \mathrm{ml}$ kaolin simulant samples can readily be generated at the maximum anticipated sample point to needle separation

- Overall solids content of needle samples taken at $57 \mathrm{ft}$ elevation falls well within $+/-5 \%$ of mean content of corresponding grab samples 


\subsection{VACUUM TESTS}

The results of the vacuum tests show a consistent overall pattern of the change in needle vacuum over time, showing a peak vacuum occurring as the sample is delivered through the needle. At this time the reason for this pattern has not been fully explained in terms of the theory of sampler operation.

It would also appear that the magnitude of the needle vacuum is not dependent upon the sampling height, but the results of the kaolin tests suggest that it increases with the SG of the liquid being sampled. 


\section{Recommendations}

The following are the principal recommendations arising from this test program:-

- Further testing should be carried out to determine the influence of sampler to sample point separation on the design of the sample tee and control systems settings for the nested, fixed-depth sampler.

- Further testing should be carried out to determine sample variability over the range of sampler to sample point separation. A more suitable simulant to investigate these effects should be considered, allied to the selection of an appropriate sample analysis technique. 


\section{References}

Reference I

Reference 2

Reference 3
AEA Technology, 'Design, Fabrication \& Demonstration of a Nested, fixeddepth Fluidic Sampler', 2926-4-001, October 1998.

Cogema Engineering Corp, 'Test Plan for Evaluating the Operational Performance of the Prototype nested, Fixed-Depth Fluidic Sampler', HNF- 3042 Rev0, 1998.

AEA Technology Engineering Services Inc., 'Sampler Supplementary Testing' 98043.06, August 1998. 


\section{Tables}

Table 1

Table 2

Table 3

Table 4

Table 5

Table 6

Table 7

Table 8

Table 9
Specified Water/Sand Simulant Particle Size Range.

Calculated Water/Sand Simulant Particle Size Range.

Sampling at 24ft with Sand Simulant (Run 2)

Sampling at $42 \mathrm{ft}$ with Sand Simulant (Run 2)

Sampling at $57 \mathrm{ft}$ with Sand Simulant (Run 2)

Sampling at $24 \mathrm{ft}$ with Sand Simulant (Run 3)

Sampling at $42 \mathrm{ft}$ with Sand Simulant (Run 3)

Sampling at $57 \mathrm{ft}$ with Sand Simulant (Run 3)

Sampling at $57 \mathrm{ft}$ with Kaolin Simulant (Run 4) 
Table 1. Specified Water/Sand Simulant Particle Size Range.

\begin{tabular}{|c|c|}
\hline Particle Size Range (microns) & $\begin{array}{c}\text { Allowable Weight Percent Solids } \\
\text { in Size Range }\end{array}$ \\
\hline$>4000 \mu \mathrm{m}$ & $0 \mathrm{wt} \%$ \\
\hline 500 to $\mathbf{4 0 0 0} \mu \mathrm{m}$ & $<1 \mathrm{wt} \%$ \\
\hline 50 to $\mathbf{5 0 0} \mu \mathrm{m}$ & $<5 \mathrm{wt} \%$ \\
\hline$<\mathbf{5 0} \mu \mathrm{m}$ & $>94 \mathrm{wt} \%$ \\
\hline
\end{tabular}

Table 2. Calculated Water/Sand Simulant Particle Size Range.

\begin{tabular}{|c|c|}
\hline Particle Size Range (microns) & $\begin{array}{c}\text { Calculated Weight Percent Solids } \\
\text { in Size Range }\end{array}$ \\
\hline \hline $5000 \mu \mathrm{m}$ & $0 \mathrm{wt} \%$ \\
\hline 500 to $\mathbf{4 0 0 0 \mu \mathrm { m }}$ & $1.35 \mathrm{wt} \%$ \\
\hline 50 to $500 \mu \mathrm{m}$ & $4.65 \mathrm{wt} \%$ \\
\hline$<50 \mu \mathrm{m}$ & $94 \mathrm{wt} \%$ \\
\hline
\end{tabular}


AEA TECHNOLOGY ENGINEERING SERVICES INC

NESTED FLXED DEPTH SAMPLER SAMPLE POINT ELEVATION TESTING

Table 3: Sampling at 24ft with Sand Simulant (Run 2)

\begin{tabular}{|c|c|c|c|c|c|c|c|c|c|c|c|}
\hline \multirow{3}{*}{\begin{tabular}{|l|} 
Elevation \\
Run No \\
Simulant \\
\end{tabular}} & \\
\hline & & & & & & & & & & & \\
\hline & \multicolumn{2}{|c|}{ 1-2 wt\% sand } & & & & & & & & & \\
\hline & & & & & & & & & & Mean & Std.Dev. \\
\hline & Needle & Grab & Grab & Grab & Grab & Grab & Grab & Grab & Grab & (Grab) & $(G r a b)$ \\
\hline & Sample & Sample1 & Sample 2 & Sample 3 & Sample 4 & Sample 5 & Sample 6 & Sample 7 & Sample 8 & & \\
\hline & & & & & & & & & & & \\
\hline Solids Content wt\% & 2.04 & 1.57 & 2.06 & 1.86 & 2.10 & 2.09 & & & & 1.94 & 0.20 \\
\hline & & & & & & & & & & & \\
\hline Particles/mi & & & & & & & & & & & \\
\hline$<50$ micron & & & & & & & & & & & \\
\hline $50-500$ micron & 0 & 1 & 10 & 4 & 9 & 16 & & & & & \\
\hline $500-4000$ micron & 0 & 0 & 0 & 0 & 0 & 2 & & & & & \\
\hline$>4000$ micron & 0 & 0 & 0 & 0 & 0 & 0 & & & & & \\
\hline Sample Volum $\mathrm{ml}$ & 500 & 40 & 40 & 40 & 40 & 40 & & & & & \\
\hline
\end{tabular}

Table 4: Sampling at $42 \mathrm{ft}$ with Sand Simulant (Run 2)

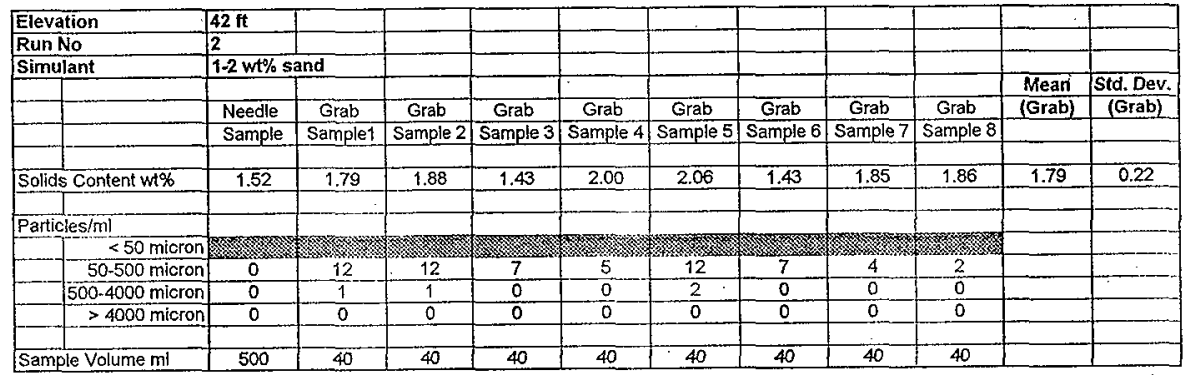

Table 5: Sampling at $57 \mathrm{ft}$ with Sand Simulant (Run 2)

\begin{tabular}{|c|c|c|c|c|c|c|c|c|c|c|c|}
\hline \multirow{2}{*}{$\begin{array}{l}\text { Elevation } \\
\text { Run No }\end{array}$} & $57 \mathrm{ft}$ & & & & & & & & & & \\
\hline & 2 & & & & & & & . & & & \\
\hline \multirow{2}{*}{ Simulant } & \multicolumn{2}{|c|}{$1.2 \mathrm{wt} \%$ sand } & & & & & & & & & \\
\hline & & & & & & & & & & Mean & Std. Dev. \\
\hline & Needle & Grab & Grab & Grab & Grab & Grab & Grab & Grab & Grab & (Grab) & (Grab) \\
\hline & Sample & Sample1 & Sample 2 & Sample 3 & Sample 4 & Sample 5 & Sample 6 & Sample 7 & Sample 8 & & \\
\hline & & & & & & & & & & & \\
\hline Solids Content wt\% & 2.26 & 2.05 & 1.89 & 1.76 & 2.06 & 1.31 & & & & 1.81 & 0.27 \\
\hline & & & & & & & & & & & \\
\hline Particles $/ m$ l & & & & & & & & & & & \\
\hline$<50$ micron & & & & & & & & & & & \\
\hline $50-500$ micron & 6 & 7 & 11 & 4 & 4 & 3 & & & & & \\
\hline $500-4000$ micron & 0 & 1 & 0 & 1 & 1 & 0 & & & & & \\
\hline$>4000$ micron & 0 & 0 & 0 & 0 & 0 & 0 & & & & & \\
\hline samn & & & & & & & & & & & \\
\hline Sample Volume m! & & & & & & & & & & & \\
\hline
\end{tabular}




\section{NESTED FIXED DEPTH SAMPLER SAMPLE POINT ELEVATION TESTING}

Table 6: Sampling at 24ft with Sand Simulant (Run 3)

\begin{tabular}{|c|c|c|c|c|c|c|c|c|c|c|c|}
\hline \multirow{2}{*}{\begin{tabular}{|l|} 
Elevation \\
Run No
\end{tabular}} & $24 \mathrm{ft}$ & & & & & & & & & & \\
\hline & 3 & & & & & & & & & & \\
\hline Simulant & \multicolumn{2}{|c|}{$10-16 \mathrm{wt} \%$ sand } & & & & & & & & & \\
\hline & & & & & & & & & & Mean & Std. Dev. \\
\hline & Needle & Grab & Grab & Grab & Grab & Grab & Grab & Grab & Grab & (Grab) & (Grab) \\
\hline & Sample & Sample1 & Sample 2 & Sample 3 & Sample 4 & Sample 5 & Sample 6 & Sample 7 & Sample 8 & & \\
\hline & & & & & & & & & & & \\
\hline Solids Content wt\% & 10.88 & 9.75 & 11.42 & 12.39 & $12 . \overline{13}$ & 11.22 & $\because$ & & & 11,38 & 0.92 \\
\hline & & & & & & & & & & & \\
\hline \multicolumn{12}{|l|}{ Particles/ml } \\
\hline \begin{tabular}{l|l} 
& $<50$ micron \\
\end{tabular} & & & & & 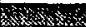 & $3:$ & & & & & \\
\hline $50-500$ micron & 0 & 7 & 3 & 1 & & & & & & & \\
\hline $500-4000$ micron & 0 & 0 & 0 & 0 & & & & & & & \\
\hline$>4000$ micron & 0 & 0 & 0 & 0 & & 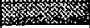 & & & & & \\
\hline & & & & & & & & & & & \\
\hline Sample Volume $\mathrm{ml}$ & 500 & 40 & 40 & 40 & 40 & 40 & & & & & \\
\hline
\end{tabular}

Table 7: Sampling at $42 \%$ with Sand Simulant (Run 3)

\begin{tabular}{|c|c|c|c|c|c|c|c|c|c|c|c|}
\hline \multirow{2}{*}{\begin{tabular}{|l|} 
Elevation \\
Run No
\end{tabular}} & $42 \mathrm{ft}$ & & & & & & & & & & \\
\hline & 1 & & & & & & & & & & \\
\hline Simulant & \multicolumn{2}{|c|}{$10-16$ wt $\%$ sand } & & & & & & & & & \\
\hline & & & & & & & & & & Mean & Std. Dev. \\
\hline & Needle & Grab & Grab & Grab & Grab & Grab & Grab & Grab & Grab & (Grab) & (Grab) \\
\hline & Sample & Sample1 & Sample 2 & Sample 3 & Sample 4 & Sample 5 & Sample 6 & Sample 7 & \begin{tabular}{|l|} 
Sample 8 \\
\end{tabular} & & \\
\hline & & & & & & & & & & & \\
\hline Solids Content wt\% & 12.06 & 12.43 & $10 . \overline{87}$ & 11.77 & 11.57 & 9.50 & & & & 11.23 & 1.00 \\
\hline & & & & & & & & & & & \\
\hline \multicolumn{12}{|l|}{ Particles/mi } \\
\hline$<50$ micron & & & $\$ 0$ & 8 & & & & & & & \\
\hline $50-500$ micron & 0 & 2 & 2 & 1 & NR & NR & & & & & \\
\hline $500-4000$ micron & 0 & 0 & 0 & 0 & $N R$ & $\overline{\mathrm{NR}}$ & & & & & \\
\hline$>4000$ micron & 0 & 0 & 0 & 0 & NR & NR & & & & & \\
\hline & & & & & & & & & & & \\
\hline Sample Volume $\mathrm{ml}$ & 500 & 40 & 40 & 40 & 40 & 40 & & & & & \\
\hline
\end{tabular}

Table 8: Sampling at 57ft with Sand Simulant (Run 3)

\begin{tabular}{|c|c|c|c|c|c|c|c|c|c|c|c|}
\hline \multirow{2}{*}{$\begin{array}{l}\text { Elevation } \\
\text { Run No }\end{array}$} & $57 \mathrm{ft}$ & & & & $\cdot$ & & & & . & & \\
\hline & 1 & & & - & & & & & & & 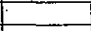 \\
\hline Simulant & \multicolumn{2}{|c|}{$10-15$ wt\% sand } & & & & & & & & & \\
\hline & & & & & & & & & & Mean & Std. Dev. \\
\hline & Needle- & Grab & Grab & Grab & Grab & Grab & Grab & Grab & Grab & (Grab) & (Grab) \\
\hline & Sample & Sample1 & Sample 2 & Sample 3 & Sample 4 & Samples & Sample 6 & Sample 7 & Sample 8 & & \\
\hline & & & & & & & & & & & \\
\hline Solids Content wt\% & 14.72 & 11.61 & 10.84 & 12.11 & 11.54 & 10.96 & 11.05 & 11.02 & & 11.30 & 0.43 \\
\hline & & & & & & & $\therefore$ & & & & \\
\hline \multicolumn{12}{|l|}{ Particles/mi } \\
\hline$<50$ micron & & & & & & & & & & & \\
\hline $50-500$ micron & 0 & 3 & 3 & 1 & NR & NR & NR & NR & & & \\
\hline $500-4000$ micron & 0 & 0 & 0 & 0 & NR & NR & NR & NR & & & \\
\hline$>4000$ micron & 0 & 0 & 0 & 0 & $\mathrm{NR}$ & $\mathrm{NR}$ & NR & NR & & & \\
\hline & & & & & & & & & & & \\
\hline Sample Volume ml & 500 & 40 & 40 & 40 & 40 & 40 & 40 & 40 & & & \\
\hline
\end{tabular}


AEA TECHNOLOGY ENGINEERING SERVICES INC

NESTED FLXED DEPTH SAMPLER SAMPLE PONNT ELEVATION TESTING

Table 9: Sampling at 57ft with Kaolin Simulant (Run 4)

\begin{tabular}{|c|c|c|c|c|c|c|c|c|c|c|c|}
\hline \multirow{2}{*}{\begin{tabular}{|l} 
Elevation \\
Run No
\end{tabular}} & $57 \mathrm{ft}$ & & & & & & & & & & \\
\hline & 1 & & & & & & & & & & \\
\hline Simulant & \multicolumn{2}{|c|}{$25-30 \mathrm{wt} \%$ clay } & & & & & & & & & \\
\hline & & & & & & & & & & Mean & Std. Dev. \\
\hline & Needle & Grab & Grab & Grab & Grab & Grab & Grab & Grab & Grab & (Grab) & (Grab) \\
\hline & Sample & Sample1 & Sample 2 & Sample 3 & Sample 4 & Sample 5 & Sample 6 & Sample 7 & Sample 8 & & \\
\hline & & & & & & & & & & & \\
\hline Sollds Content wt\% & 25.12 & 24.13 & 24.84 & 24.50 & 24.90 & 24.21 & 24.49 & 23.97 & & 24.43 & 0.33 \\
\hline Particles/ml & & & & & & & & & & & \\
\hline$<50$ micron & & & & & & & & & & & \\
\hline $50-500$ micron & & & & & & & & & & & \\
\hline $500-4000$ micron & & & & & & & & & & & \\
\hline$>4000$ micron & & & & & & & & & & & \\
\hline & & & & & & & & & & & \\
\hline Sample Volume ml & 500 & 40 & 40 & 40 & 40 & 40 & 40 & 40 & & & \\
\hline
\end{tabular}

Indicates reading unobtainable due to excessive numbers of particles 


\section{Photographs}

\begin{tabular}{|c|c|}
\hline Photograph 1 & RFD Pump Assembly \\
\hline Photograph 2 & RFD Attached to Charge Vessel \\
\hline Photograph 3 & Sampler Assembly in Supply Tank \\
\hline Photograph 4 & Mechanical Mixer in Supply tank \\
\hline Photograph 5 & Sample Tee \\
\hline Photograph 6 & Sample Tee Mounted on Crane Basket \\
\hline Photograph 7 & Sampler Testing at $57 \mathrm{ft}$ Elevation \\
\hline Photograph 8 & Fragments of Scale Contaminant \\
\hline Photograph 9 & Sample Delivery at $57 \mathrm{ft}$ Elevation \\
\hline Photograph 10 & Full Sample Bottle at $57 \mathrm{ft}$ Elevation \\
\hline
\end{tabular}


HNF-3864, REV. 0

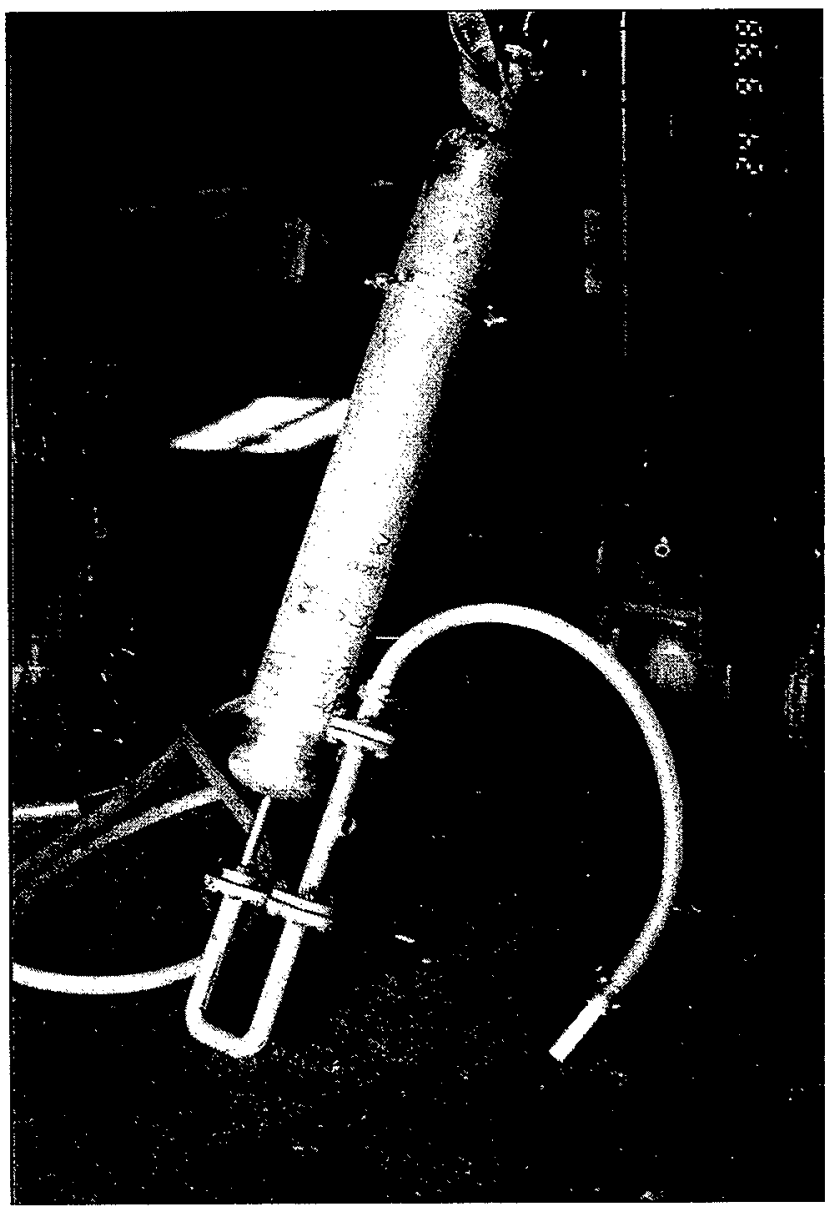

PHOTOGRAPH 1: RFD PUMP ASSEMBLY 


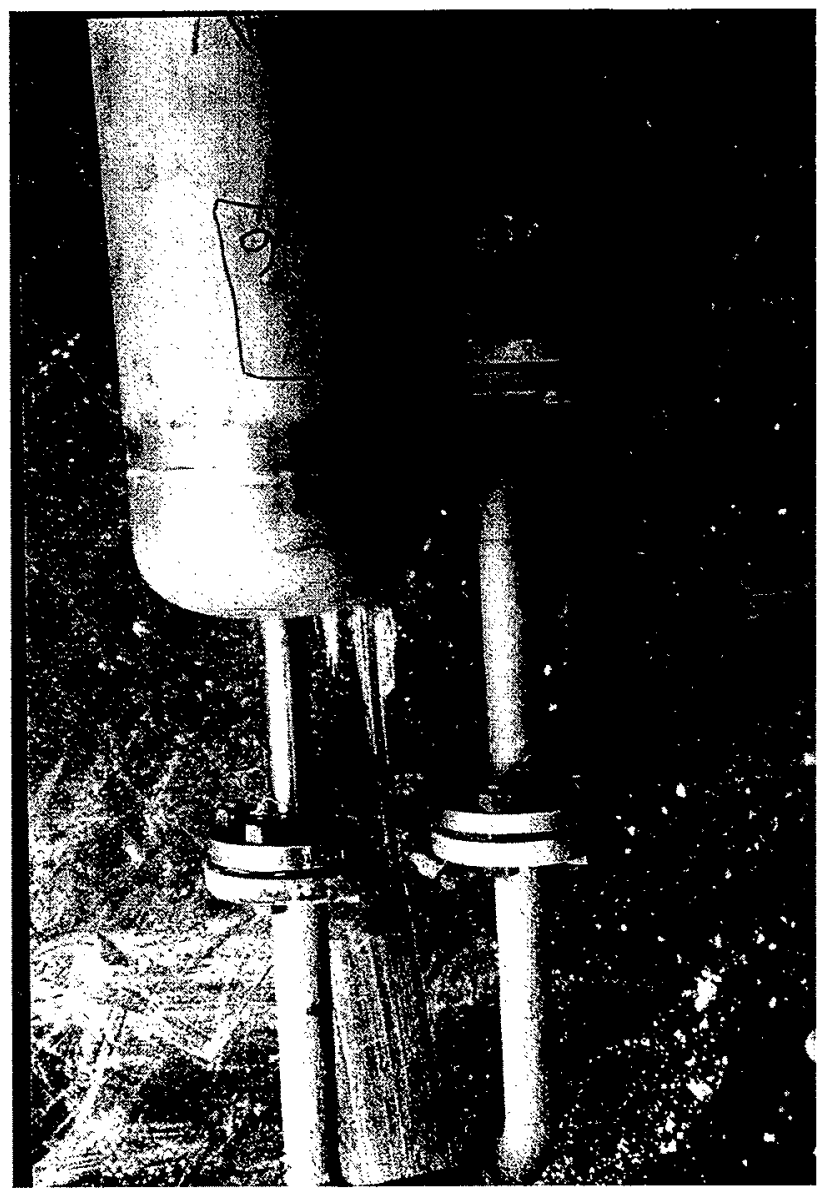

PHOTOGRAPH 2: RFD ATTACHED TO CHARGE VESSEL 


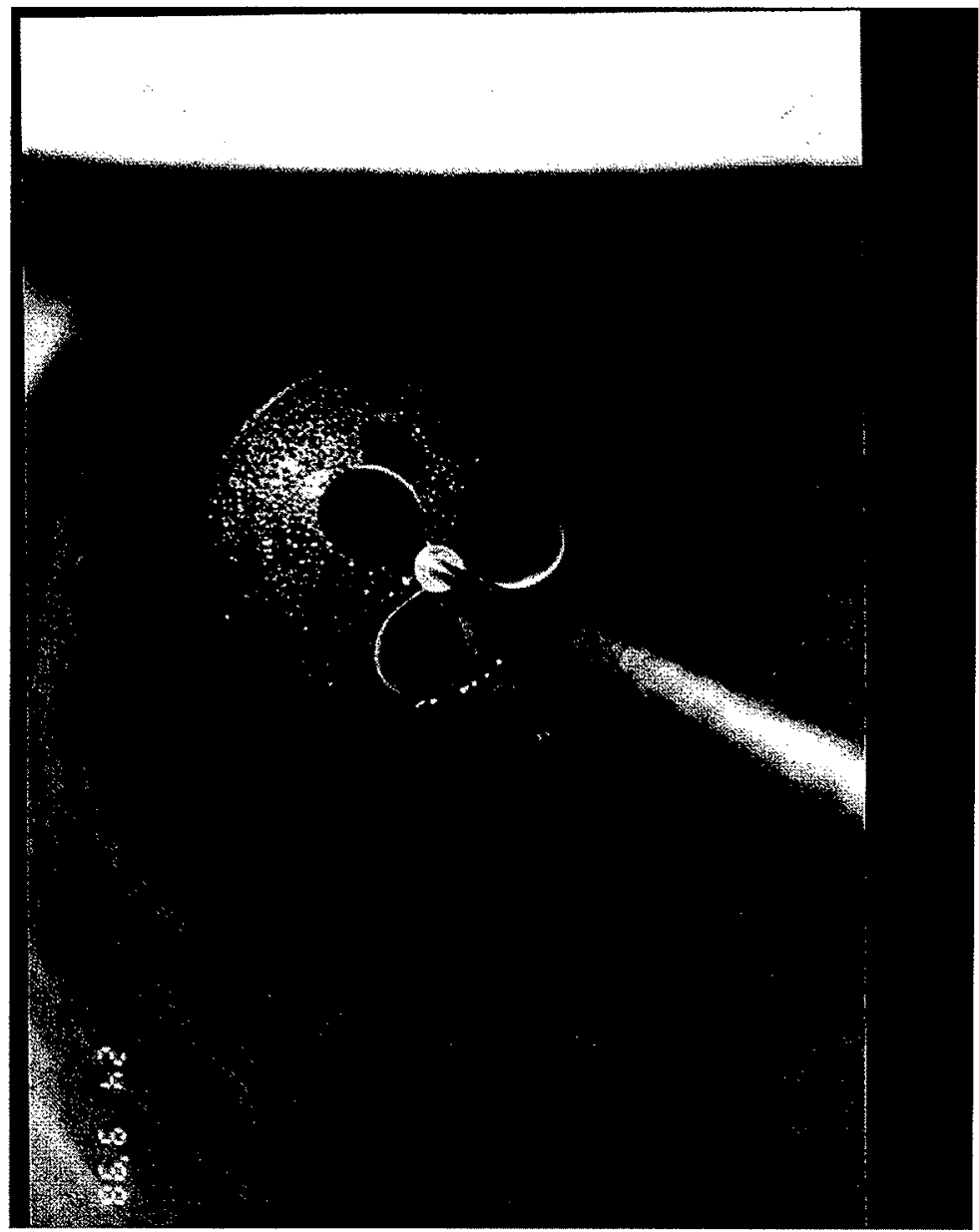

PHOTOGRAPH 3: MECHANICAL MIXER IN SUPPLY TANK 


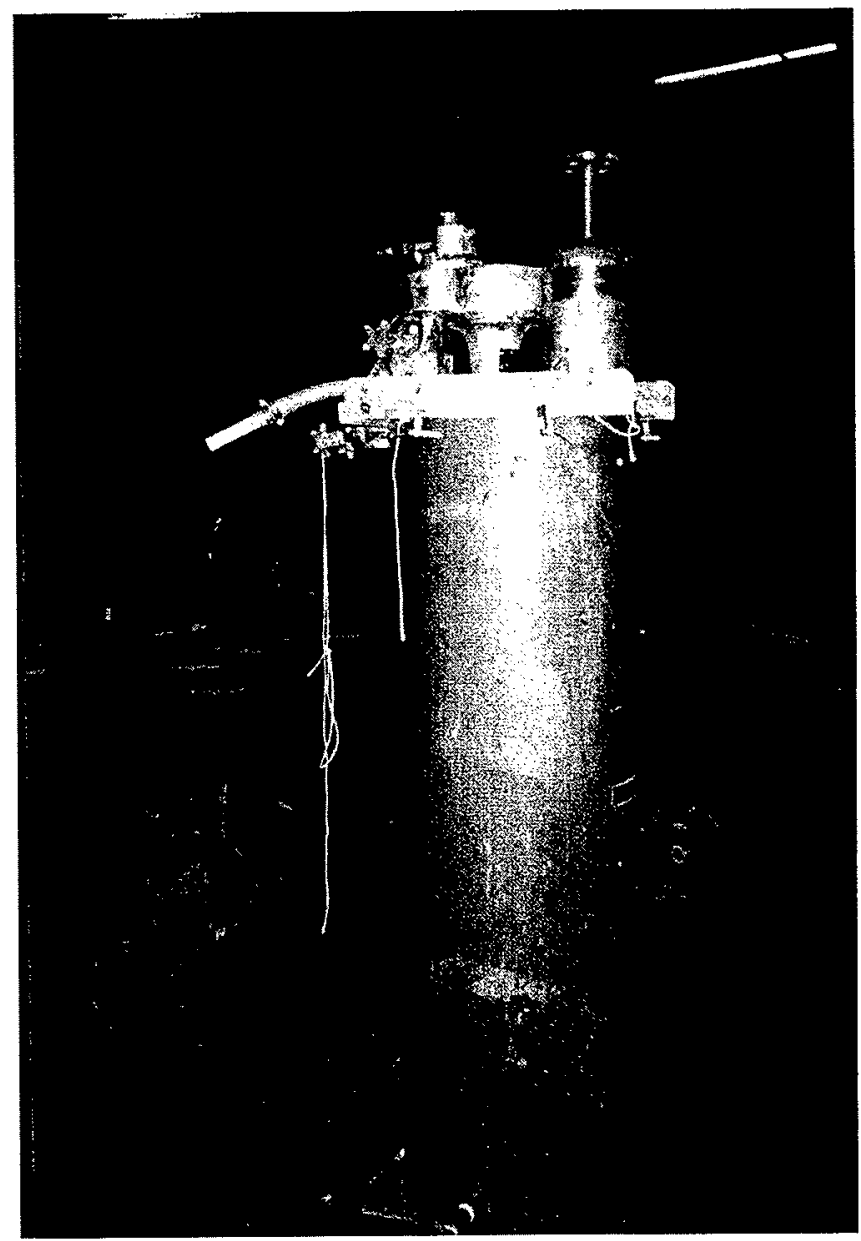

PHOTOGRAPH 4: SAMPLER ASSEMBLY IN SUPPLY TANK 


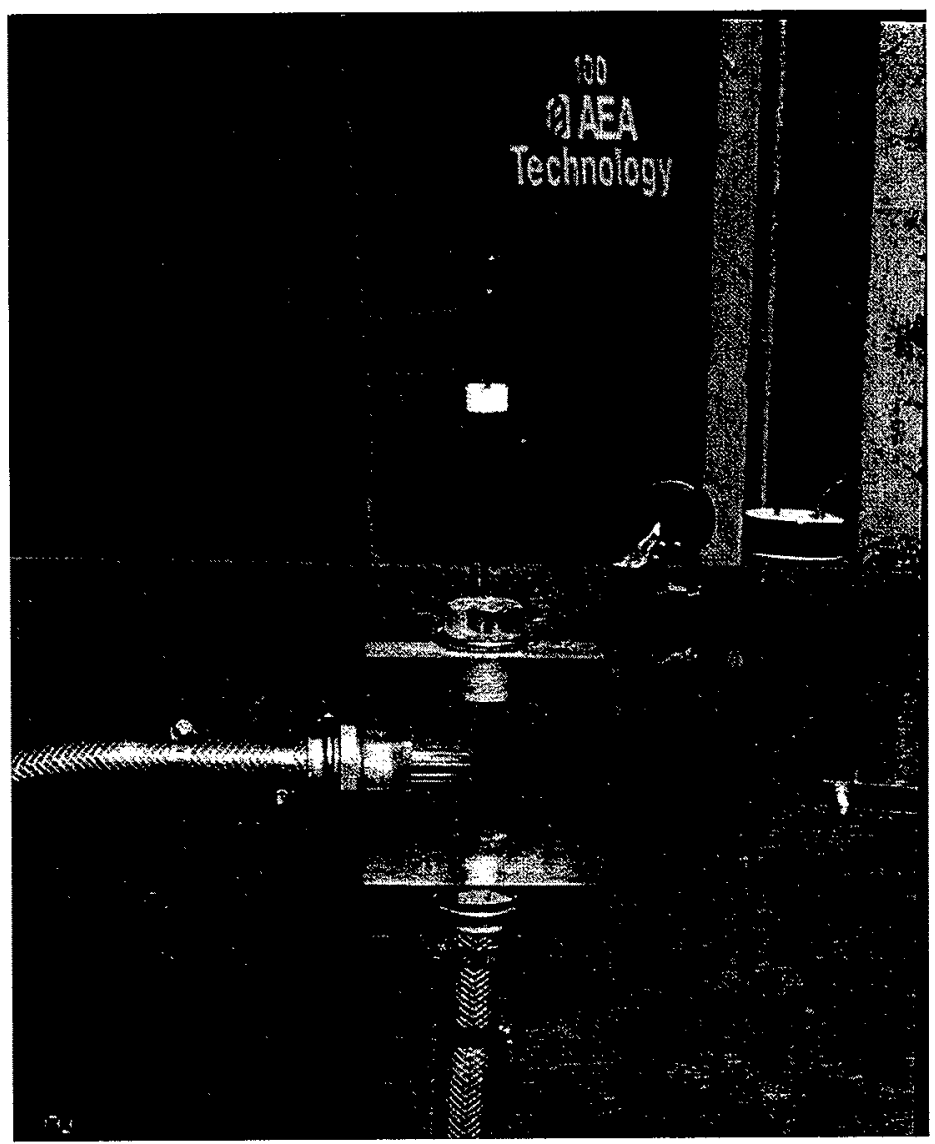

PHOTOGRAPH 5: SAMPLE TEE 


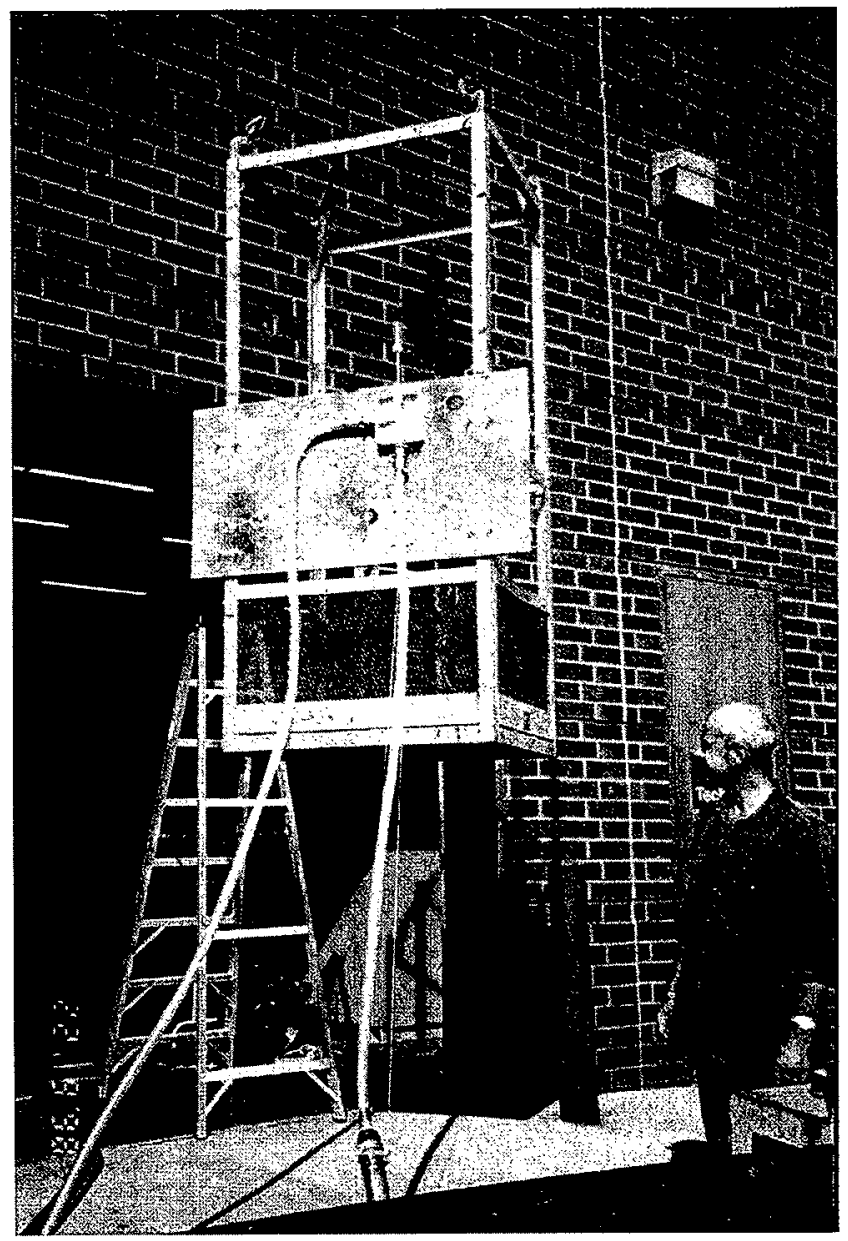

PHOTOGRAPH 6: SAMPLE TEE MOUNTED ON CRANE BASKET 


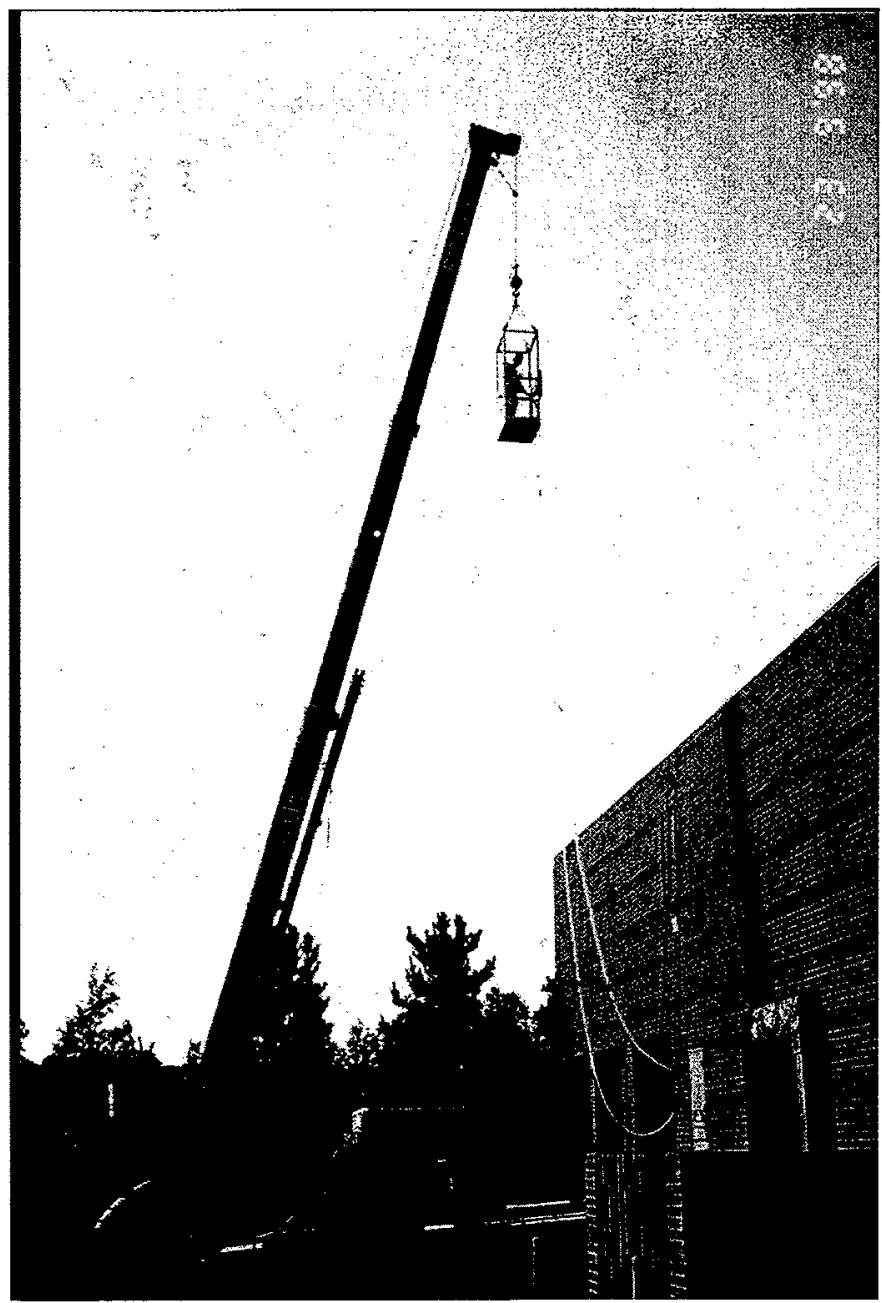

PHOTOGRAPH 7: SAMPLER TESTING AT 57ft ELEVATION 


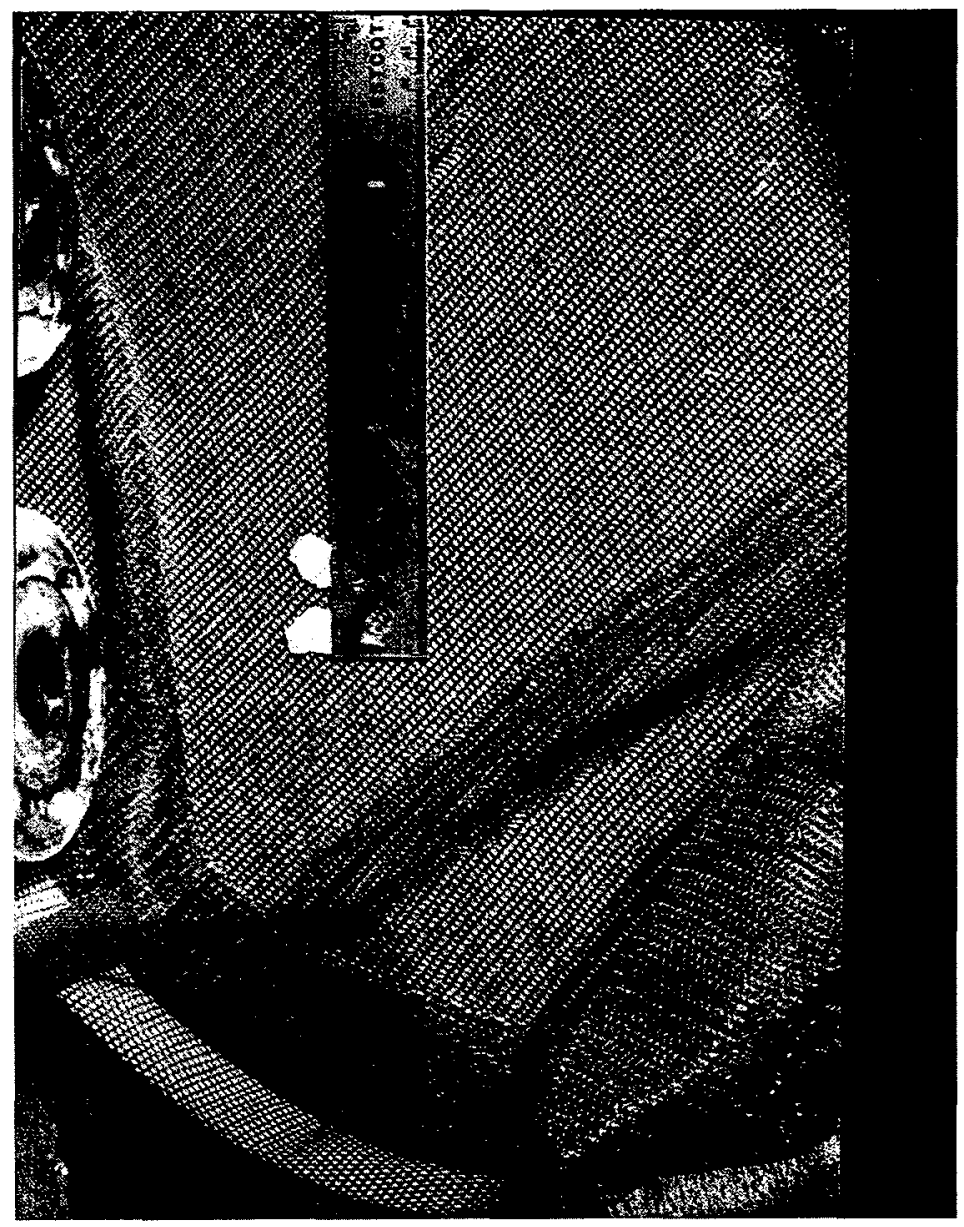

PHOTOGRAPH 8: FRAGMENTS OF SCALE CONTAMINATION 


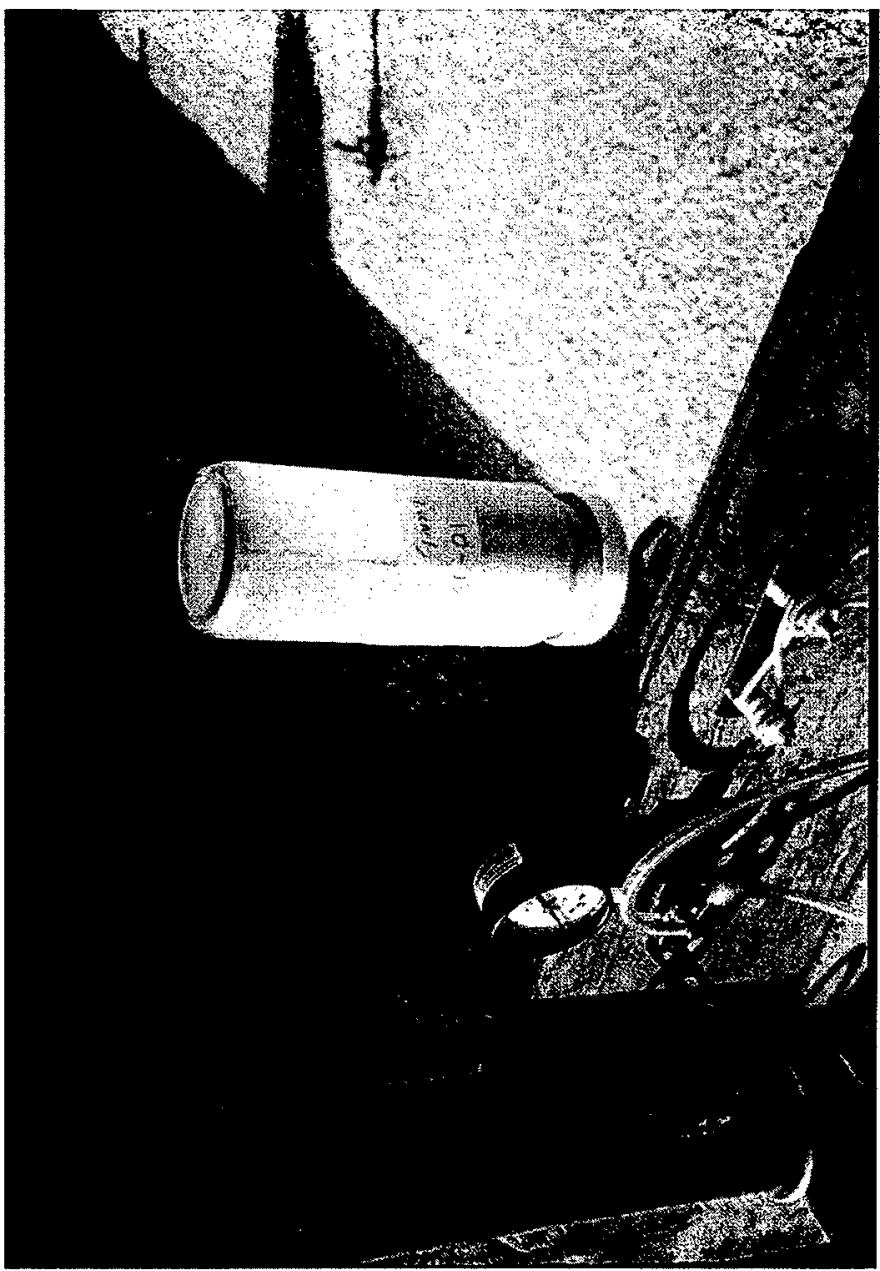

PHOTOGRAPH 9: SAMPLE DELIVERY AT 57ft ELEVATION 


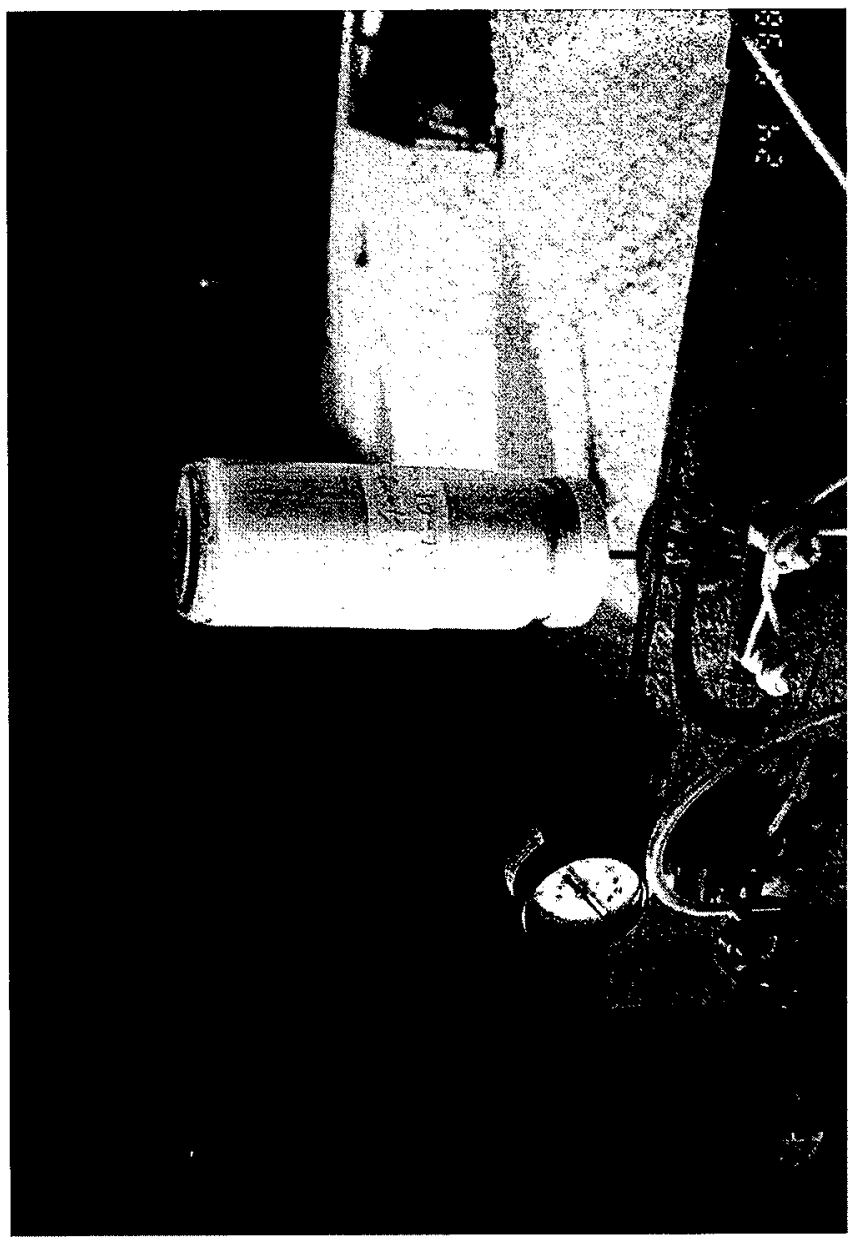

PHOTOGRAPH 10: FULL SAMPLE BOTTLE AT $57 \mathrm{ft}$ ELEVATION 
HNF-3864, Rev. 0

\section{DISTRIBUTION}

Number of copies

Offsite

1

Ames Laboratory

125 Spedding Hall

Iowa State University

Ames, IA 50011

G. J. Bastiaans

1

U. S .Department of Energy-Federal Energy

Technology Center FETC-MGN

3610 Collins Ferry road

Morgantown, WV 26507-0880

R. K. Staubley

1

Lockheed Idaho Technical Company

765 Lindsay Boulevard

Idaho Falls, ID 83403

T. R. Thomas

1

Oak Ridge National Laboratory

P. O. Box 2008

Oak Ridge, TN 37831-6044

Dr. Sharon M. Robinson

2

Westinghouse Savannah River Corporation

Savannah River Technology Center, 703H Bldg. Aiken, SC 29808

J. P. Morin

R. C. Fowler

ONSITE

4

U.S. Department of Energy, Richland Operations Office
R. Carreon
$\mathrm{A} 0-21$
C. S. Louie
A0-21
J. F. Thompson, Jr.
S7-54N.
N. C. Welliver
A $0-21$

DoE Public Reading Room $\quad$ H2-53

Distr 1 
HNF-3864, Rev. 0

1

5

1

5

3

Orig. + 1
Fluor Daniel Hanford Inc.

S. K. Foreman $\quad$ K9-46

Lockheed Martin Hanford Inc.

J. N. Appel

A3-03

R. G. Brown

S7-12

K. A. Gasper

A3-03

G. P. Janicek

S7-12

J. S. Schofield

S7-12

Numatec Hanford Corporation

R. M. Boger

S7-12

Pacific Northwest National Laboratory
S. A. Bailey K5-08
B. A. Carteret K9-91
R. L. Gilchrist K9-91
M. R. Powell K.6-24

COGEMA Engineering Corporation
F. R. Reich
H3-26
G. A. Ritter
S7-12
J. L. Smalley
S7-12

Central Fjles

B1-07 